\title{
Concentração de propriedade e emissão de ação: Evidência da América Latina
}

\author{
Ownership concentration and share issue: Evidence from Latin America
}

\author{
Vicente Lima Crisóstomo ${ }^{\dagger}$ \\ Bruno Goes Pinheiro \\ Wilson Toshiro Nakamura*
}

\begin{abstract}
Resumo O trabalho objetiva identificar o efeito da concentração de propriedade sobre a emissão de ação da empresa latino-americana. Para uma amostra de 887 empresas os resultados indicam que a concentração de propriedade inibe a emissão de ação na América Latina. Além disto, a rentabilidade também inibe a de emissão de ação, sendo indicação de um comportamento pecking order. O tamanho da empresa, por sua vez, favorece a capacidade de emissão de ação. Verificou-se também que empresas com mais oportunidades de crescimento são mais emissoras de ação, o que indica possível esgotamento fluxo de caixa e da capacidade de financiar-se com dívida. Adicionalmente, a disponibilidade de ativos tangíveis para garantia de empréstimos é desfavorável à emissão de ação, sinalizando que empresas que dispõem de ativos parecem preferir dívida a emitir ação. Por fim, a pesquisa contribui para o debate sobre o tema estrutura de capital, especificamente sobre a emissão de ação, ao prover evidência adicional sobre a empresa da América Latina.
\end{abstract}

Palavras-chave: Emissão de ação; Concentração de propriedade; Determinantes; América Latina.

Código JEL: G31, G32, G39.

\begin{abstract}
This paper aims to identify the effect of ownership concentration on share issuance of Latin American firms. For a sample of 887 firms, the results indicate that ownership concentration hinders share issuance in Latin America. Profitability also curbs share issuance, indicating a pecking order behavior. Firm size favors firms' ability to issue shares. We also find that firms with more growth opportunities tend to issue more shares, which suggests a possible depletion of available cash flow and less capability to contract debt. Additionally, the availability of assets to guarantee loans hampers share issuance, signaling that firms with tangible assets seem to prefer debt rather than share issuance. Finally, this work contributes to the debate on capital structure, specifically about share issuance, by providing additional evidence on Latin American firms.
\end{abstract}

Keywords: Share issuance; Ownership concentration; Determinants; Latin America. JEL Code: G31, G32, G39.

Submitted on March 14, 2020. Revised on June 19, 2020. Accepted on October 2nd, 2020. Published online in December 2020. Editor in charge: Paulo Renato Terra.

$\dagger$ Universidade Federal do Ceará - Brazil: vlceuf c. br

¥ Banco do Nordeste do Brasil \& Universidade Federal do Ceará - Brazil: brunogoesp@gmail .com

${ }^{*}$ Universidade Presbiteriana Mackenzie - Brazil: wilson. nakamura@mackenzie.br 


\section{Introdução}

A importância da estrutura de capital para as empresas tem sido discutida com maior frequência após a metade do século XX, tendo como marco inicial as proposições da irrelevância das decisões de estrutura de capital (Modigliani and Miller; 1958). A partir de então, tem-se encontrado evidência da relevância das decisões sobre estrutura de capital para a empresa (Barclay and Smith; 2005; Harris and Raviv; 1991; Myers; 2003). Esta importância tem impulsionado pesquisa sobre a relação entre empresa e o mercado de financiamento (Akerlof; 1970; Stein; 2003). O desenvolvimento do mercado financeiro tem sido apontado como impulsionador do desenvolvimento econômico ao melhorar o direcionamento de fundos para financiar a atividade produtiva (Beck et al.; 2000; Wurgler; 2000). Há também evidência de que o desenvolvimento financeiro está sujeito a influência de fatores como a melhor proteção a investidores, a estabilidade monetária, e a nuances do ambiente institucional (Ahmed and Courtis; 1999; La Porta et al.; 1997). A existência de fatores que restringem o desenvolvimento do mercado financeiro e suas possibilidades de financiamento empresarial motiva a pesquisa sobre fontes de financiamento e estrutura de capital em mercados como a América Latina.

Países da América Latina passaram por importantes transformações políticas, econômicas e sociais nas últimas décadas, depois de muitos regimes ditatoriais, obtendo melhorias em termos de estabilidade política e monetária como também no desenvolvimento do mercado de capitais, apresentando ambiente institucional com semelhanças ao mesmo tempo que se identifica especificidades em cada um (Bastos and Nakamura; 2009; Bastos et al.; 2009; Borda et al.; 2017; Carneiro and Brenes; 2014; Cuervo-Cazurra; 2008; Terra; 2007, 2009).

A estrutura de financiamento das empresas de países da América Latina, caracteristicamente de regime de Lei Civil, apresenta tendência a estar baseada em crédito bancário, sendo os mercados de capitais da região ainda pouco desenvolvidos comparativamente a economias mais desenvolvidas (Beck et al.; 2000; Boadi et al.; 2019; Saona and San Martín; 2016).

Especialmente em mercados em desenvolvimento, a análise dos fatores determinantes da escolha de fontes de financiamento das empresas é apontada como relevante, considerando que as teorias a respeito da estrutura de capital têm sido elaboradas com base em economias desenvolvidas (Albanez and Valle; 2009; Brito et al.; 2007; Medeiros and Daher; 2008). Conflitos de agência decorrentes da divergência de interesses entre acionistas e gestores, bem como entre acionistas majoritários e minoritários, têm sido apontados como fatores que podem interferir na estrutura de capital da empresa (Jensen; 
1986; Stein; 2003; Stulz; 1990). A empresa latino-americana é caracterizada pela alta concentração de propriedade o que influencia os conflitos de agência com possíveis reflexos na estrutura de capital destas empresas. O objetivo deste trabalho é avaliar um eixo ainda pouco explorado, notadamente em mercados em desenvolvimento, que é o efeito da concentração de propriedade sobre a capacidade de emissão de ação da empresa latino-americana à luz das Teorias da Agência e Pecking order ao articular a preferência por fontes de financiamento e os conflitos de agência.

Para uma amostra de 5.715 observações anuais de 887 empresas não financeiras listadas em bolsas da América Latina no período 1994-2015, os resultados indicam que a concentração de propriedade restringe a emissão de ação das empresas latino-americanas. Adicionalmente, a rentabilidade tem efeito negativo sobre a emissão de ação, enquanto o tamanho da empresa favorece a capacidade de emissão de ação, da mesma forma que a presença de boas oportunidades de crescimento mostra-se capaz de impulsionar a emissão de ação nestes mercados.

Este trabalho apresenta algumas contribuições para a literatura. Primeiro, ele expande a pesquisa sobre a decisão de financiamento da empresa no cenário latino-americano, um importante contexto de países em desenvolvimento, ao analisar a decisão sobre a emissão de ação, ainda muito pouco explorada nestes países. Segundo, o trabalho analisa a decisão de financiamento através de emissão de ação sob o enfoque de agência ao levar em conta a concentração de propriedade. A decisão de emissão de ação é também observada sob a óptica da Teoria Pecking Order ao considerar-se a influência da rentabilidade e de outros fatores tidos como relevantes para decisões sobre financiamento.

\section{Revisão de literatura e hipóteses}

\subsection{Teorias associadas à emissão de ação}

A emissão de ação é uma importante fonte de financiamento da empresa sendo mais intensamente utilizada em mercados desenvolvidos do que em mercados em desenvolvimento que apresentam mercados de capitais ainda menos avançados como pode ser observado pelos números sobre capitalização de mercado por PIB e número de empresas listadas em bolsa por 10.000 habitantes de cada país (Cheung; 2016). Nesta classificação, os países latinoamericanos estão em posições inferiores sinalizando que estes são mercados ainda em estágios iniciais comparados com os de países desenvolvidos. De um modo geral, as bolsas de valores da América Latina são caracterizadas pelo baixo volume de negócios, baixa liquidez e pouca oferta pública inicial de ações (IPO) (Santiago-Castro and Brown; 2007). 
A utilização da emissão de ação como fonte de financiamento é tratada pela Teoria Pecking order que prevê uma preferência por fontes de financiamento a serem utilizadas para financiar os projetos de investimento da empresa de acordo com o custo da fonte de financiamento, tanto financeiro como informativo (Myers; 1984; Myers and Majluf; 1984). Sob este enfoque, o custo financeiro e informativo da emissão de ação faz com que esta alternativa seja utilizada somente após esgotar-se a possibilidade de usar-se fluxo de caixa e endividamento. O endividamento, por sua vez, é proposto como uma forma de financiamento atrativa levando em consideração o benefício tributário da mesma como prevê a Teoria Trade-off (Shyam-Sunder and Myers; 1999). Além dos fatores inerentes a cada possível fonte de financiamento, os conflitos de agência têm sido apontados também como capazes de interferir na estrutura de capital da empresa (Driffield et al.; 2007).

A conotação informativa e de sinalização está presente fortemente na escolha da fonte de financiamento. Endividamento transmite sinal positivo sobre a empresa uma vez que indica sua capacidade de obtenção de crédito. A emissão de ação, por sua vez, pode ter uma leitura negativa a partir da interpretação de que a empresa estaria com escassez de fluxo de caixa e/ou dificuldade de obtenção de dívida (Albanez and Valle; 2009). Por outro lado, a emissão de ação também pode ser vista como a empresa aproveitando uma situação favorável de mercado em relação à empresa que visa proteger os atuais acionistas como preconiza o enfoque teórico market timing (Asquith and Mullins; 1986; Mikkelson and Partch; 1986) o que é um indício de conflito de agência associado à estrutura de capital. Evidência inicial foi encontrada sobre o comportamento oportunista da empresa com relação à emissão de ação (Eid Júnior; 1996) como também evidência no sentido contrário, tem apontado o pouco desenvolvimento do mercado de capitais brasileiro, que conta com poucas empresas listadas em bolsa e baixa liquidez das ações, como fator que dificulta esta análise (Mendes et al.; 2009).

\subsection{Atributos da empresa latino-americana e a emissão de ação}

\subsubsection{Concentração de propriedade}

A estrutura de propriedade da empresa e a divergência de objetivos entre acionistas controladores e minoritários têm sido sugeridas como capazes de ter influência na condução de decisões a respeito da forma de financiamento dos projetos da empresa por questões associadas a interesses de acionistas e de investidores externos (Claessens et al.; 2000; Driffield et al.; 2007; La Porta et al.; 1999, 2000; Morck et al.; 1988).

Em mercados com alta concentração de propriedade, característica esta que costuma estar associada à presença de acionistas controladores na gestão 
da empresa, os acionistas minoritários estão mais suscetíveis a problemas de expropriação devido ao elevado número de benefícios privados de controle acessíveis aos controladores, e à inadequada proteção a acionistas minoritários (Dyck and Zingales; 2004; La Porta et al.; 2000, 1998; Young et al.; 2008). Esta reduzida proteção ao acionista minoritário contribui para o pouco interesse de investidores externos o que pode ter efeito desfavorável para a captação de recursos através da emissão de ação (Ahmed and Courtis; 1999). Outro fator que também pode prejudicar a emissão de ação é o receio de perda de controle por parte de acionistas controladores que podem ver na emissão de ação uma ameaça ao seu poder na empresa (Crisóstomo and Pinheiro; 2015; Ganguli; 2013).

A América Latina, majoritariamente composta por países de sistema legal Lei Civil (Civil Law), tende a ter exacerbado o conflito de interesse entre acionistas majoritários e minoritários, diferentemente de países anglo-saxões nos quais o conflito predominante é entre os gestores e os acionistas (Young et al.; 2008). Evidência prévia em mercados emergentes mostra que, de fato, parece haver uma maior propensão ao uso de dívida e fluxo de caixa para financiar a atividade produtiva. Este é o caso da Índia, no qual acionistas majoritários preferem o uso de dívida à emissão de ação (Ganguli; 2013). Resultados na mesma direção também foram encontrados nos países da América Latina (Argentina, Brasil, Chile, Colômbia, México, Peru e Venezuela) nos quais se observou um efeito positivo da concentração de propriedade sobre o endividamento, o que sinaliza a resistência de grandes acionistas à emissão de ação por receio de perda de controle da empresa. Estes achados foram consistentes em todos os países, sendo mais relevantes no Brasil e no Chile (Céspedes et al.; 2010; Crisóstomo and Pinheiro; 2015).

Esta argumentação, aliada às particularidades do mercado latino-americano, motiva a proposição da hipótese de que a concentração de propriedade é desfavorável à emissão de ação em mercados da América Latina, como expresso a seguir:

Hipótese 1: A concentração de propriedade da empresa latinoamericana está relacionada com a menor propensão à emissão de ação.

\subsubsection{Rentabilidade}

Elevada rentabilidade da empresa tende a estar associada com mais alta disponibilidade de fluxo de caixa que é uma importante fonte de financiamento para projetos de investimento da empresa em função de seu mais baixo custo financeiro e informativo. De fato, a Teoria Pecking order prevê uma 
preferência da empresa por esta fonte de financiamento (Myers; 1984; Myers and Majluf; 1984). Esta proposição tem sido amparada pela pesquisa que tem documentado evidência de que empresas mais rentáveis tendem a apresentar mais baixos níveis de endividamento e de emissão de ação uma vez que o lucro gerado internamente na empresa é atrativo com fonte de financiamento (Bevan and Danbolt; 2002; Correa et al.; 2013; Haron; 2014; Titman and Wessels; 1988).

Esta argumentação a respeito da preferência de uso de lucro retido para financiar investimento, somada ao pouco desenvolvimento do mercado de capitais na América Latina, motiva a proposição da hipótese de que a empresa latino-americana tende a apresentar um comportamento pecking order, que se traduz numa associação negativa entre a rentabilidade e a emissão de ação da empresa.

Hipótese 2: A rentabilidade está relacionada com a menor propensão à emissão de ação da empresa latino-americana.

\subsubsection{Tamanho da empresa}

O tamanho é um atributo da empresa sugerido como capaz de influenciar na capacidade de acesso ao financiamento externo em virtude de alguns fatores associados a empresas de maior porte (Rajan and Zingales; 1995): mais disponibilidade de garantias (collateral) que facilita o acesso à dívida; mais disponibilidade de fluxo de caixa, o que também demonstra mais capacidade para honrar dívidas; já contar com histórico da empresa no mercado, o que melhora a sua relação com as instituições de financiamento e investidores em geral.

Especificamente, com relação à captação de financiamento através da emissão de ação, empresas de maior porte, devido a sua mais forte presença no mercado, tendem a ter menos assimetria informativa o que contribui para menos custo de emissão de ação (de Haan and Hinloopen; 2003). Outro fator favorável à emissão de ação por empresas maiores é a diversificação que elas tendem a apresentar em mais alta intensidade que empresas menores, sendo a diversificação considerada como fator que reduz o risco de falência da empresa (Titman and Wessels; 1988).

Estes argumentos, notadamente a história e reputação da empresa, são ainda mais marcantes em mercados emergentes nos quais observa-se mais elevada concentração de propriedade e há menos investidores externos. Empresas de menor porte teriam mais dificuldade de relacionar-se com as instituições de mercado e potenciais investidores, tendo que encarar um custo informativo bem mais elevado ao apresentar seus projetos de investimento e 
situação financeira. Assim, tem-se suporte à proposição da hipótese de que o tamanho da empresa é favorável à captação de fundos através da emissão de ação, como a seguir expresso:

Hipótese 3: O tamanho da empresa da empresa latino-americana está relacionado com sua mais alta propensão a emitir ação.

\subsubsection{Oportunidades de crescimento}

Ao dispor de bons projetos de investimento a empresa buscará as fontes de financiamento disponíveis para viabilizar a execução destes projetos e, assim, maximizar suas oportunidades de crescimento. No cenário de muitas oportunidades de crescimento é provável que a empresa esgote sua capacidade de uso de fluxo de caixa e deva recorrer ao endividamento externo. Levando em consideração a prevenção contra o risco de falência decorrente do uso excessivo de endividamento e sua capacidade de contratação de dívida, a empresa terá um limite prudencial para seu uso de dívida para evitar custos de falência e de sub investimento (Myers; 1977). Aproximando-se deste limite e, tendo como base seus bons projetos de investimento, a empresa pode optar pela emissão de ação. Os bons projetos devem ser subjacentes à emissão de ação em qualquer mercado, seja desenvolvido ou em desenvolvimento (Gonenc and Hermes; 2008).

É plausível esperar-se que as oportunidades de investimento da empresa da América Latina esgotem a disponibilidade de fluxo de caixa para financiar o investimento como também possa levar ao limite prudencial de uso de endividamento e, assim, suscitar o processo de emissão de ação como sugerido a seguir:

Hipótese 4: As oportunidades de crescimento da empresa latinoamericana estão relacionadas com sua mais alta propensão a emitir ação.

\subsubsection{Endividamento}

Sob o arcabouço da Teoria Pecking Order, há uma hierarquia das fontes de financiamento da empresa. A opção por financiamento externo, endividamento e/ou emissão de ação, é considerada pela empresa como alternativa após esta exaurir sua capacidade de financiar seus projetos com fluxo de caixa disponível, em função de custo financeiro e informativo (Myers; 1977; Myers and Majluf; 1984). O uso de fluxo de caixa é atraente por seu mais baixo custo financeiro e informativo uma vez que a empresa só precisará divulgar seus projetos para os acionistas que têm interesse no ganho de capital. Mais 
elevada tributação de dividendos também pode impulsionar a retenção de lucros para investimento uma vez que acionistas podem ver ganhos de capital como mais relevantes que dividendos (Bond and Meghir; 1994). A eventual insuficiência de fluxo de caixa para suprir a necessidade de financiamento da empresa faz com que esta recorra endividamento e/ou emissão de ação. A dívida apresenta a vantagem tributária que tem que ser balanceada com o problema do risco de sub-investimento (underinvestment) e de falência decorrente de alto nível de endividamento (Barclay and Smith; 2005). Alternativamente ao uso de dívida, a empresa pode optar pela emissão de ação que pode ter efeitos de sinalização, positiva ou negativa, junto ao mercado, relacionados com a temporização de mercado que é muito usual em mercados de capitais avançados (Baker et al.; 2003; Ross; 1977). É plausível esperar-se que as oportunidades de investimento da empresa latino-americana, como em outros mercados, esgotem a disponibilidade de fluxo de caixa e demandem financiamento externo. Nesta situação a empresa precisa avaliar o limite prudencial de uso de endividamento como também os aspectos envolvidos na emissão de ação que tem nuances associadas a problemas de agência. Em mercados com alta concentração de propriedade, como é o caso da América Latina, acionistas controladores têm receio de perder o poder sobre a empresa, podendo a emissão de ação e a diluição de capital ameaçar este poder. Este receio favorece a preferência por financiamento através de fluxo de caixa ou dívida (Ganguli; 2013). Neste sentido, resultados em distintos países, incluindo latino-americanos, têm documentado uma correlação positiva entre endividamento e concentração de propriedade (Bokpin and Arko; 2009; Brailsford et al.; 2002; Céspedes et al.; 2010). Esta resistência à emissão de ação por grandes acionistas, muito presentes na empresa latino-americana, ampara a proposição de que empresa latino-americana vai explorar sua capacidade de endividamento antes de recorrer à emissão de ação, de tal maneira que prevê-se uma melhor capacidade de endividamento reduzirá a propensão da empresa a emitir ação como a seguir explicitado:

Hipótese 5: O endividamento da empresa latino-americana está relacionado com sua mais baixa propensão a emitir ação.

\subsubsection{Tangibilidade}

A disponibilidade de ativos tangíveis que possam ser usados como garantia (collateral) é muito relevante para a captação de dívida como a literatura tem documentado evidência (Albanez and Valle; 2009; Chen; 2004; Rajan and Zingales; 1995). Por sua vez, a emissão de ação não requer ativos como garantia. No processo de emissão de ação, os projetos de investimento 
Tabela 1

Distribuição da amostra por país

\begin{tabular}{lrrrrr}
\hline país & n. empresas & $\%$ & n. observ. & $\%$ & período coberto \\
\hline Argentina & 27 & 3,05 & 122 & 2,13 & $2009-2015$ \\
Brasil & 435 & 49,04 & 3.460 & 60,54 & $1996-2015$ \\
Chile & 162 & 18,26 & 741 & 12,97 & $1996-2015$ \\
Colômbia & 33 & 3,72 & 229 & 4,01 & $1996-1015$ \\
México & 93 & 10,48 & 213 & 3,73 & $2012-2015$ \\
Peru & 137 & 15,45 & 950 & 16,62 & $1994-2015$ \\
total & 887 & 100,00 & 5.715 & 100,00 & $1994-2015$ \\
\hline
\end{tabular}

subjacentes é que são realmente importantes, além da reputação da empresa que também pode ter papel considerável. Assim, a disponibilidade de ativos tangíveis será um estímulo ao endividamento e um desincentivo à emissão de ações, principalmente em mercados como os da América Latina com alta concentração de propriedade e mercados de capitais ainda em desenvolvimento, como proposto na hipótese expressa a seguir:

Hipótese 6: A disponibilidade de ativos tangíveis da empresa latino-americana está relacionada com sua mais baixa propensão a emitir ação.

\section{Metodologia}

\subsection{Amostra}

A amostra compreende empresas listadas nas bolsas de valores da Argentina, Brasil, Chile, Colômbia, México e Peru. Estes países são as seis maiores economias da América Latina, mensuradas pelo PIB a preços correntes de $2017^{1}$. A amostra compreende 5.715 observações de 887 empresas não financeiras. Os dados financeiros, de emissão de ação, e de concentração de propriedade foram obtidos do sistema de dados da Economática®. Empresas do setor financeiro (bancos, companhias de seguros e de investimento) foram excluídas da amostra por suas especificidades relativas à estrutura de capital. A Tabela 1 apresenta a distribuição da amostra por país.

\subsection{Modelo e variáveis}

Para contrastar empiricamente as hipóteses propostas, modelos logit baseados no modelo da equação (1) são estimados. A variável dependente emissão de ação (EMI_AÇÃ $\mathrm{O}_{i, t}$ ) é operacionalizada como uma variável dummy,

\footnotetext{
${ }^{1}$ Dados do Banco Mundial de 2017 obtidos em https : / data. worldbank . org/indic ator $/$ ny $\cdot$ gdp. mktp. cd ?end=2017\&start $=1960 \& v i e w=$ chart
} 
à qual é atribuído valor 1 se a empresa $i$ emitiu ação no ano $t$, e 0 em caso contrário. Esta pesquisa foi feita observando a quantidade de ações da empresa comparativamente à quantidade do ano anterior. A variação positiva na quantidade de ações indica emissão de ação pela empresa, interpretação esta que segue relevantes trabalhos anteriores (de Haan and Hinloopen; 2003; Gonenc and Hermes; 2008). Variação negativa na quantidade de ações motivou consulta adicional aos eventos da empresa para verificação de eventuais agrupamentos com lançamento de ação concomitantemente, o que também indica emissão de ação.

Utilizou-se Regressão Logística dado que a variável dependente é uma variável dummy. A técnica pode ser definida como sendo utilizada para verificar o comportamento entre uma variável dependente que é binária e variáveis independentes, métricas ou não. O modelo se propõe a investigar o efeito das variáveis explicativas em relação à probabilidade de ocorrência de um determinado evento de interesse que é definido pela variável dependente (Fávero et al.; 2009). A regressão logística fornece um método eficiente para lidar com essa situação (Hair et al.; 2009). Assim, o modelo da equação (1) avalia a influência dos fatores explicativos sobre a probabilidade da empresa emitir ação.

$$
\begin{gathered}
\operatorname{Pr}\left(\text { EMI_AÇÃO }{ }_{i, t}=1 \mid \boldsymbol{x}_{i, t}\right)=f\left(\boldsymbol{x}_{i, t}^{\prime} \boldsymbol{\beta}\right)+\mu_{i, t} \\
\boldsymbol{\beta}=\left[\begin{array}{c}
\beta_{0} \\
\beta_{1} \\
\beta_{2} \\
\vdots \\
\beta_{6} \\
1 \\
1 \\
1
\end{array}\right] \quad \boldsymbol{x}_{i, t}=\left[\begin{array}{c}
1 \\
\mathrm{CPROP}_{i, t} \\
\operatorname{ROA}_{i, t} \\
\operatorname{TAM}_{i, t} \\
\operatorname{OPCRESC}_{i, t} \\
\operatorname{ENDIV}_{i, t} \\
\operatorname{TANG}_{i, t} \\
\operatorname{DP}_{i, t} \\
\operatorname{DS}_{i, t} \\
\operatorname{DA}_{i, t}
\end{array}\right]
\end{gathered}
$$

No modelo da equação (1), $\mathrm{CPROP}_{i, t}$ corresponde aos níveis de concentração de propriedade da empresa $i$ no ano $t$. O modelo é estimado para a presença de um acionista majoritário que é aproximado por uma variável dummy (ACMAJOR) para a qual é atribuído 1 se a empresa $i$ tem um acionista com mais de $50 \%$ das ações com voto no ano $t$, e 0 em caso contrário. Estima-se também o modelo para cada um dos cinco níveis de concentração acionária adotados no estudo: concentração de propriedade com poder de 
voto em mãos do primeiro acionista (CPROP1), dos dois principais acionistas (CPROP2), e assim por diante, até os cinco principais acionistas (CPROP5). $\mathrm{ROA}_{i, t}$ é a rentabilidade da empresa $i$ no ano $t$, medida pelo retorno dos ativos (EBIT/Ativo Total). TAM TA $_{i, t}$ é tamanho da empresa $i$ no ano $t$, mensurado pelo logaritmo natural do ativo total da mesma. OPCRESC OP, $_{i, t}$ corresponde às oportunidades de crescimento da empresa $i$ no ano $t$, mensuradas pela razão entre a soma do valor de mercado com o passivo exigível, e, o ativo total da empresa. ENDIV $_{i, t}$ é o endividamento, calculado pelo quociente entre a dívida de longo prazo e o total de ativos da empresa. TANG $i, t$ é a tangibilidade da empresa $i$ no ano $t$, medida pelo quociente entre ativo imobilizado e ativo total. DP, DS e DA são, respectivamente, variáveis dicotômicas de país, setor e ano, e $\mu_{i, t}$ é o termo de erro.

Modelos são estimados para a amostra contendo todos os países da amostra (América Latina) e separadamente, com o intuito de verificar possíveis peculiaridades de cada um deles. Todos os modelos têm variáveis de controle temporal (dummy de ano) e setorial (dummy de setor), e nos modelos da América Latina (amostra completa) são utilizadas dummy de país.

\section{Análise dos resultados}

\subsection{Análise descritiva}

A Tabela 2 apresenta a estatística descritiva das características das empresas da América Latina: concentração de propriedade com poder de voto em mãos do primeiro acionista (CPROP1 a CPROP5), rentabilidade (ROA), tamanho (TAM), oportunidades de crescimento (OPCRESC), endividamento (ENDIV) e tangibilidade (TANG). Pode-se observar que há alta concentração de propriedade (CPROP) nos mercados latino-americanos. O maior acionista com voto (CPROP1) detém, em média, 53,4\% das ações da empresa, e esta concentração chega a 77,39\% do capital com voto detido pelos cinco maiores acionistas (CPROP5).

As médias de rentabilidade (ROA) e tangibilidade (TANG) são de 7,24\% e $29,89 \%$, respectivamente. Pode-se observar uma elevada dispersão da amostra em termos de tamanho o que é importante para o estudo no sentido evitar viés de porte de empresa.

A Tabela 3 exibe números relativos à alta concentração de propriedade por país em ordem decrescente de concentração de capital com voto nas mãos do principal acionista, o que está de acordo com a proporção de empresas com a presença de um acionista majoritário. Observa-se a elevada concentração de propriedade em todos os países e destaca-se a presença do acionista majoritário que chega a $87 \%$ na Argentina e $60 \%$ no Brasil. 
Tabela 2

Estatística descritiva da América Latina

\begin{tabular}{lrrrrrrr}
\hline variável & n. observ. & média & desvio padrão & coef. de variação & mediana & mínimo & máximo \\
\hline CPROP1 & 5.715 & 0,5340 & 0,2676 & 0,5011 & 0,5227 & 0,0014 & 1,0000 \\
CPROP2 & 5.715 & 0,6680 & 0,2508 & 0,3755 & 0,6971 & 0,0014 & 1,0000 \\
CPROP3 & 5.715 & 0,7250 & 0,2319 & 0,3198 & 0,7631 & 0,0014 & 1,0000 \\
CPROP4 & 5.715 & 0,7561 & 0,2176 & 0,2878 & 0,8085 & 0,0014 & 1,0000 \\
CPROP5 & 5.715 & 0,7739 & 0,2083 & 0,2691 & 0,8287 & 0,0014 & 1,0000 \\
ROA & 5.696 & 0,0724 & 0,1203 & 1,6618 & 0,0659 & $-0,7134$ & 1,2662 \\
TAM & 5.715 & 13,0536 & 1,7365 & 0,1330 & 13,0626 & 6,6516 & 19,4506 \\
OPCRESC & 5.715 & 0,9931 & 0,8728 & 0,8789 & 0,7530 & 0,0127 & 5,9325 \\
ENDIV & 4.934 & 0,1319 & 0,1231 & 0,9333 & 0,0986 & 0,0000 & 0,8958 \\
TANG & 5.708 & 0,2989 & 0,2472 & 0,8270 & 0,2687 & 0,0000 & 0,9770 \\
\hline
\end{tabular}

Tabela 3

Concentração de propriedade por país

\begin{tabular}{|c|c|c|c|c|c|c|c|c|}
\hline \multirow{2}{*}{ país } & \multirow{2}{*}{ CPROP1 } & \multirow{2}{*}{ CPROP2 } & \multirow{2}{*}{ CPROP3 } & \multirow{2}{*}{ CPROP4 } & \multirow{2}{*}{ CPROP5 } & \multicolumn{2}{|c|}{ acionista majoritário } & \multirow{2}{*}{ total } \\
\hline & & & & & & não há & há & \\
\hline Argentina & 0,7022 & 0,7285 & 0,7378 & 0,7378 & 0,7378 & $16(13 \%)$ & $106(87 \%)$ & 122 \\
\hline Brasil & 0,5573 & 0,6952 & 0,7522 & 0,7812 & 0,7955 & $1.378(40 \%)$ & $2.082(60 \%)$ & 3.460 \\
\hline Peru & 0,5303 & 0,6721 & 0,7286 & 0,7595 & 0,7778 & $419(44 \%)$ & $531(56 \%)$ & 950 \\
\hline México & 0,4737 & 0,5621 & 0,5915 & 0,6082 & 0,6214 & $104(49 \%)$ & $109(51 \%)$ & 213 \\
\hline Chile & 0,4702 & 0,6108 & 0,6798 & 0,7248 & 0,7578 & $401(54 \%)$ & $340(46 \%)$ & 741 \\
\hline Colômbia & 0,3709 & 0,4923 & 0,5632 & 0,6117 & 0,6455 & $167(73 \%)$ & $62(27 \%)$ & 229 \\
\hline total & 0,5340 & 0,6680 & 0,7250 & 0,7561 & 0,7739 & $2.485(43 \%)$ & $3.230(57 \%)$ & 5.715 \\
\hline
\end{tabular}

A Tabela 4 apresenta uma análise detalhada da proporção de acionistas que detêm o controle da empresa, ou seja, que chegam a ter mais de $50 \%$ do capital votante, em cada país. Os números exibidos confirmam a alta concentração de propriedade. Do coletivo de países latino-americanos, 57\% das empresas têm seu controle nas mãos de um só acionista. Este número chega a $74 \%$ e $81 \%$ ao considerar-se dois e três acionistas, respectivamente. Estes resultados revelam o excesso de poder que poucos acionistas controladores têm nas empresas destes países, o que pode ter reflexo na estrutura de capital, e em outras políticas, das empresas.

Tabela 4

Número de acionistas que detêm mais de $50 \%$ das ações com direito a voto

\begin{tabular}{|c|c|c|c|c|c|c|c|}
\hline país & 1 & 2 & 3 & 4 & 5 & $>5$ & Total \\
\hline Argentina & $106(87 \%)$ & $6(92 \%)$ & $0(92 \%)$ & $0(92 \%)$ & $0(92 \%)$ & $10(100 \%)$ & 122 \\
\hline Brasil & $2.082(60 \%)$ & $637(79 \%)$ & $220(85 \%)$ & $129(89 \%)$ & $75(91 \%)$ & $317(100 \%)$ & 3.460 \\
\hline Peru & $531(56 \%)$ & $142(71 \%)$ & $50(76 \%)$ & $45(81 \%)$ & $35(85 \%)$ & $147(100 \%)$ & 950 \\
\hline México & $109(51 \%)$ & $25(63 \%)$ & $12(69 \%)$ & $10(73 \%)$ & $2(74 \%)$ & $55(100 \%)$ & 213 \\
\hline Chile & $340(46 \%)$ & $161(68 \%)$ & $82(79 \%)$ & $38(84 \%)$ & $41(89 \%)$ & $79(100 \%)$ & 741 \\
\hline Colômbia & $62(27 \%)$ & $41(50 \%)$ & $32(59 \%)$ & $12(64 \%)$ & $15(71 \%)$ & $67(100 \%)$ & 229 \\
\hline total & $3.230(57 \%)$ & $1.012(74 \%)$ & $396(81 \%)$ & $234(85 \%)$ & $168(88 \%)$ & $675(100 \%)$ & 5.715 \\
\hline
\end{tabular}

Nota: \% acumulado de acionistas com mais de $50 \%$ de ações ordinárias (entre parênteses). 
Tabela 5

Emissão de ação da empresa latino-americana

\begin{tabular}{lrrr}
\hline \multirow{2}{*}{ país } & \multicolumn{2}{c}{ emissão de ação } & \multirow{2}{*}{ total } \\
\cline { 2 - 3 } & \multicolumn{1}{c}{ não } & \multicolumn{1}{c}{ sim } & \\
\hline Peru & $560(60 \%)$ & $373(40 \%)$ & 933 \\
Colômbia & $154(68 \%)$ & $71(32 \%)$ & 225 \\
Brasil & $2.539(74 \%)$ & $893(26 \%)$ & 3.432 \\
Argentina & $100(82 \%)$ & $22(18 \%)$ & 122 \\
Chile & $601(82 \%)$ & $132(18 \%)$ & 733 \\
México & $178(87 \%)$ & $27(13 \%)$ & 205 \\
Total & $4.132(73 \%)$ & $1.518(27 \%)$ & 5.650 \\
\hline
\end{tabular}

O mercado latino-americano caracteriza-se pela pouca proteção legal aos acionistas minoritários (La Porta et al.; 1998), ao mesmo tempo em que os controladores podem fazer uso de sua elevada concentração de propriedade para proteger seus interesses podendo até, em casos mais desfavoráveis, haver expropriação da riqueza dos acionistas minoritários através do uso indevido de benefícios privados de controle (Dyck and Zingales; 2004; Salzmann and Soypak; 2017).

Na Tabela 5 tem-se a lista de países em ordem decrescente de proporção de empresas emitentes de ação. Observa-se que há pouca emissão de ação nas empresas da América Latina, o que pode dever-se ao receio de perda de controle por parte de grandes acionistas como também pelo pouco interesse, e/ou receio, de pequenos investidores em arriscar-se a investir em ações de empresas com alta concentração de propriedade. Assim, estas empresas podem emitir ação somente em janelas de boas oportunidades que poderiam estar associadas a períodos com altos níveis de preços das ações no mercado como proposto pela Teoria Market timing (Oliveira and Kayo; 2015; Oliveira and Martelanc; 2014).

\subsection{Fatores determinantes da emissão de ação}

A Tabela 6 apresenta a estimação dos modelos que avaliam os fatores determinantes da emissão de ação na América Latina. Verifica-se que a concentração de propriedade (ACMAJOR; CPROP1; CPROP2; CPROP3; CPROP4; CPROP5) tem um significante efeito negativo sobre a propensão a emitir ação da empresa latino-americana, como sugerido (Hipótese 1), podendo este efeito dever-se ao receio de perda de controle e/ou a falta de interesse de pequenos investidores sob o arcabouço teórico de que conflitos de agência, de fato, interferem na escolha da fonte de financiamento (Ganguli; 2013). Estes fatores desmotivadores da emissão de ação por parte de empresas da Amé- 
rica Latina podem também contribuir para que estes mercados sejam considerados como baseados no crédito bancário, como a literatura tem documentado (Beck et al.; 2000; Boadi et al.; 2019; Saona and San Martín; 2016). Observa-se que a presença de um acionista com mais de 50\% do capital com voto (ACMAJOR) tem forte efeito redutor da propensão da empresa latinoamericana a emitir ação. Este mesmo efeito é observado ao considerar-se a concentração de propriedade nas mãos do principal acionista (CPROP1) que está muito próximo da presença de um majoritário (ACMAJOR), como também nas mãos dos dois até os cinco principais acionistas com voto (CPROP2; CPROP3; CPROP4; CPROP5). Esta elevada concentração de poder de voto envolve interesses de poder de controle e sua manutenção, o que se concretiza através de estruturas piramidais de propriedade, propriedade cruzada, emissão de ações sem direito de votos e acordos de acionistas (Crisóstomo and Brandão; 2019; Young et al.; 2008).

Como sugerido (Hipótese 2), a rentabilidade (ROA) apresenta um efeito negativo sobre a propensão da empresa latino-américa em realizar processo de emissão de ação, o que está em conformidade com a proposta da Teoria Pecking order. Assim, a empresa latino-americana estaria preferindo a utilização de fluxo de caixa para financiar os seus projetos de investimento. Este efeito é confirmado em estudos com distintos países (Bevan and Danbolt; 2002; de Haan and Hinloopen; 2003; Gonenc and Hermes; 2008).

Pode-se observar também que o tamanho da empresa (TAM) é fator que aumenta a probabilidade da empresa emitir ação, como sugerido (Hipótese 3) em função da possível menor assimetria informativa destas empresas e seu menor risco de falência que deixa investidores externos mais seguros, o que está em sintonia com resultados anteriores em outros mercados (de Haan and Hinloopen; 2003; Titman and Wessels; 1988).

Como proposto (Hipótese 4), as oportunidades de crescimento (OPCRESC) da empresa latino-americana são capazes de impulsionar a probabilidade da empresa realizar emissão de ação, indicando que empresas com mais projetos de investimento, de fato, estariam demandando mais recursos do que aqueles acessíveis através da disponibilidade de fluxo de caixa e de sua capacidade de endividamento.

O efeito negativo do endividamento da empresa latino-americana sobre sua propensão a emitir ação (Hipótese 5) não foi observado. Há que se notar que estas empresas operam em mercados com tendência a financiamento baseado no crédito bancário que ainda contam com mercado de bolsa de valores menos ativos comparativamente a mercados desenvolvidos (Beck et al.; 2000; Boadi et al.; 2019; Saona and San Martín; 2016). Estas características destes mercados, aliadas ao possível receio de perda de poder sobre a empresa 
Tabela 6

Estimação de modelos da emissão de ação na América Latina

\begin{tabular}{|c|c|c|c|c|c|c|}
\hline variável & (i) & (ii) & (iii) & (iv) & (v) & (vi) \\
\hline ACMAJOR & $\begin{array}{c}-0,1920 * * * \\
(0,074)\end{array}$ & & & & & \\
\hline CPROP1 & & $\begin{array}{c}-0,4204 * * * * \\
(0,144)\end{array}$ & & & & \\
\hline CPROP2 & & & $\begin{array}{c}-0,7787 * * * \\
(0,149)\end{array}$ & & & \\
\hline CPROP3 & & & & $\begin{array}{c}-1,0124 * * * \\
(0,160)\end{array}$ & & \\
\hline CPROP4 & & & & & $\begin{array}{c}-1,1271 \text { **** } \\
(0,169)\end{array}$ & \\
\hline CPROP5 & & & & & & $\begin{array}{c}-1,1997 * * * \\
(0,176)\end{array}$ \\
\hline ROA & $\begin{array}{c}-2,5718 * * * \\
(0,386)\end{array}$ & $\begin{array}{c}-2,5537 * * * \\
(0,387)\end{array}$ & $\begin{array}{c}-2,5178 * * * \\
(0,388)\end{array}$ & $\begin{array}{c}-2,5299 * * * \\
(0,391)\end{array}$ & $\begin{array}{c}-2,5389 * * * \\
(0,392)\end{array}$ & $\begin{array}{c}-2,5405 * * * \\
(0,392)\end{array}$ \\
\hline TAM & $\begin{array}{l}0,2244 * * * \\
(0,026)\end{array}$ & $\begin{array}{l}0,2191 * * * \\
(0,026)\end{array}$ & $\begin{array}{l}0,2154 * * * \\
(0,026)\end{array}$ & $\begin{array}{l}0,2108 * * * \\
(0,026)\end{array}$ & $\begin{array}{l}0,2067 * * * \\
(0,026)\end{array}$ & $\begin{array}{l}0,2042^{* * * *} \\
(0,026)\end{array}$ \\
\hline OPCRESC & $\begin{array}{l}0,3686 * * * \\
(0,048)\end{array}$ & $\begin{array}{l}0,3651 * * * \\
(0,048)\end{array}$ & $\begin{array}{l}0,3536 * * * \\
(0,048)\end{array}$ & $\begin{array}{l}0,3507 * * * \\
(0,048)\end{array}$ & $\begin{array}{l}0,3515^{* * * *} \\
(0,048)\end{array}$ & $\begin{array}{l}0,3498 * * * \\
(0,048)\end{array}$ \\
\hline ENDIV & $\begin{array}{r}0,0198 \\
(0,299)\end{array}$ & $\begin{array}{r}0,0326 \\
(0,298)\end{array}$ & $\begin{array}{r}0,0201 \\
(0,298)\end{array}$ & $\begin{array}{r}0,0166 \\
(0,299)\end{array}$ & $\begin{array}{r}0,0195 \\
(0,299)\end{array}$ & $\begin{array}{r}0,0178 \\
(0,299)\end{array}$ \\
\hline TANG & $\begin{array}{c}-0,9742 * * * \\
(0,173)\end{array}$ & $\begin{array}{c}-0,9618 * * * \\
(0,173)\end{array}$ & $\begin{array}{c}-0,9267 * * * \\
(0,173)\end{array}$ & $\begin{array}{c}-0,9117 * * * \\
(0,173)\end{array}$ & $\begin{array}{c}-0,9121 * * * \\
(0,173)\end{array}$ & $\begin{array}{c}-0,9111 * * * \\
(0,173)\end{array}$ \\
\hline n. obs. & 4859 & 4859 & 4859 & 4859 & 4859 & 4859 \\
\hline pseudo R2 & 0,090 & 0,090 & 0,093 & 0,096 & 0,096 & 0,097 \\
\hline Wald chi2(43) & 393,38 & 394,71 & 412,10 & 424,04 & 428,00 & 429,30 \\
\hline p-value & 0,000 & 0,000 & 0,000 & 0,000 & 0,000 & 0,000 \\
\hline
\end{tabular}

Notas: A variável dependente é a emissão de ação (EMI_AÇÃO). Variáveis independentes: acionista majoritário (ACMAJOR); concentração de propriedade nas mãos do principal acionista (CPROP1); concentração de propriedade nas mãos dos dois principais acionistas (CPROP2); concentração de propriedade nas mãos dos três principais acionistas (CPROP3); concentração de propriedade nas mãos dos quatro principais acionistas (CPROP4); concentração de propriedade nas mãos dos cinco principais acionistas (CPROP5); rentabilidade (ROA); tamanho (TAM); oportunidades de crescimento (OPCRESC); endividamento (ENDIV); tangibilidade (TANG). Foram estimados modelos logit. Coeficientes estimados e desvios padrões robustos à heteroscedasticidade (entre parênteses) referentes à estimação do modelo da equação (1). Modelos incluem dummies de país, setor e ano. ***, ** e * denotam significância estatística dos coeficientes em $1 \%, 5 \%$ e $10 \%$, respectivamente. 
por parte de acionistas controladores em mercados em desenvolvimento (Crisóstomo and Pinheiro; 2015; Ganguli; 2013), podem justificam a preferência por uso de fluxo de caixa para financiamento destas empresa em detrimento de emissão de ações. Quanto à decisão por endividamento ou emissão de ação, a falta de sensibilidade entre endividamento e emissão de ação pode ser um sinal de indiferença destas empresas por uma ou outra forma de captação de recursos. Isto motivou a realização de testes adicionais. De fato, a comparação de médias não indicou diferença de nível de endividamento entre empresas emissoras e não emissoras de ação. Modelos alternativos, estimados por mínimos quadrados ordinários robustos a heteroscedasticidade, tendo-se o endividamento como variável dependente, também não mostraram sensibilidade do endividamento à emissão de ação (modelos não exibidos por limitação de espaço). Nestas estimações, destaca-se o efeito negativo da rentabilidade sobre o endividamento, equivalente ao observado sobre a emissão de ação, o que aponta a provável prioridade do uso de lucro retido para o financiamento. Também destaca-se o mais elevado uso de crédito bancário por empresas com mais oportunidades de crescimento e de maior porte. $\mathrm{O}$ elemento diferenciador é a disponibilidade de ativos tangíveis (TANG) que figura como elemento que favorece bastante o endividamento em contraste com seu efeito negativo sobre a emissão de ação. Desta forma, diante da possível indiferença da empresa latino-americana entre financiar-se por dívida ou emissão de ação, a disponibilidade de ativos tangíveis, aliada à resistência a pulverizar o capital por parte de grandes acionistas, parece contribuir para que as empresas tenham preferência por dívida.

Como esperado (Hipótese 6), observou-se um efeito negativo da disponibilidade de ativos tangíveis da empresa para serem usados como garantia de empréstimos (TANG) sobre a propensão da empresa a emitir ação. De fato, a tangibilidade de ativos parece ser fator que favorece o uso de dívida para financiar investimento de modo que sua mais alta disponibilidade motiva o uso de dívida e desestimula a emissão de ações nas empresas latino-americanas.

As Tabelas 7 a 12 apresentam os modelos estimados para cada país, no intuito de se ter uma análise mais detalhada sobre a influência da concentração de propriedade e de outros fatores sobre a propensão da emissão de ação em cada país. Apesar do conjunto de países da América Latina ter uma tendência de orientação ao financiamento por crédito bancário, evidência prévia mostra que o endividamento tem uma dinâmica que varia entre países neste entorno (Bogéa Sobrinho et al.; 2012) o que sugere a possibilidade da dinâmica de emissão de ação também poder apresentar alguma variação.

Pode-se observar que a empresa brasileira tem um comportamento que segue os resultados obtidos para o completo coletivo de empresas latino- 
americanas (Tabela 7). Nota-se, entretanto, uma atenuação do efeito negativo da estrutura de propriedade que, de modo similar ao que ocorre no Peru (Tabela 8), não se manifesta na concentração de poder até o segundo maior acionista e manifesta-se fortemente para a concentração de poder de voto nas mãos dos três principais até o quinto acionista. Isto pode dever-se ao fato de que acordos de controle, envolvendo três ou mais acionistas, estejam celebrando-se com a preocupação de manutenção da estrutura de controle e, assim, evitando-se ameaças a ela o que pode decorrer de processos de emissão de ação. Observe-se ainda que, no Brasil, há um efeito negativo do nível de endividamento sobre a probabilidade de emissão de ação como sugerido (Hipótese 5) sinalizando que, neste mercado, a preferência por uso de dívida é ainda mais marcante em detrimento à emissão de ação. Empresas do Peru (Tabela 8) também apresentam comportamento similar exceto pela insensibilidade da emissão de ação ao tamanho da empresa (TAM) e ao endividamento (ENDIV).

No Chile (Tabela 9), confirma-se o forte efeito negativo da concentração de propriedade, em todos os níveis, sobre a probabilidade de emissão de ação de suas empresas. Além disto, observa-se situação equivalente ao conjunto latino-americano, exceto pelo fato de observar-se uma mais frágil influência das oportunidades de crescimento (OPCRESC) que ali não menos impulsionadoras de processos de emissão de ação (Tabela 9).

Por outro lado, as empresas da Argentina (Tabela 10), tendem a preferir fortemente a financiar-se com dívida em detrimento a emissão de ação como se vê pelo efeito negativo do nível de endividamento sobre a probabilidade de emissão de ação (Hipótese 5). Contrariamente aos demais países, há uma suave tendência de empresas de maior porte serem mais resistentes, ou menos capazes, de emitir ações. Afora estes dois aspectos, a empresa argentina parece ter seu processo de emissão de ações indiferente à concentração acionária com poder de voto, à rentabilidade e à tangibilidade de seus ativos.

$\mathrm{Na}$ Colômbia (Tabela 11), a presença de um acionista majoritário mostra um forte efeito contrário à emissão de ação como previsto. Entretanto, este resultado não é observado quando considera-se a proporção de ações nas mãos dos principais acionistas. Para empresas colombianas, as oportunidades de crescimento (OPCRESC) mostram-se fator estimulador da emissão de ação. Afora isto, estas empresas têm sua emissão de ação praticamente insensível aos demais fatores considerados.

O processo de emissão de ação da empresa mexicana, por sua vez (Tabela 12), só não é insensível às oportunidades de crescimento. No México, contrariamente ao observado para o coletivo de empresas latino-americanas, as oportunidades de crescimento apresentam uma suave tendência a inibir a 
Tabela 7

Estimação de modelos da emissão de ação no Brasil

\begin{tabular}{|c|c|c|c|c|c|c|}
\hline variável & (i) & (ii) & (iii) & (iv) & (v) & (vi) \\
\hline ACMAJOR & $\begin{array}{l}0,0250 \\
(0,094)\end{array}$ & & & & & \\
\hline CPROP1 & & $\begin{array}{r}0,0356 \\
(0,181)\end{array}$ & & & & \\
\hline CPROP2 & & & $\begin{array}{r}-0,2796 \\
(0,197)\end{array}$ & & & \\
\hline CPROP3 & & & & $\begin{array}{c}-0,5281^{* *} \\
(0,215)\end{array}$ & & \\
\hline CPROP4 & & & & & $\begin{array}{c}-0,6448^{* * * *} \\
(0,229)\end{array}$ & \\
\hline CPROP5 & & & & & & $\begin{array}{l}-0,7373^{*} * * \\
(0,238)\end{array}$ \\
\hline ROA & $\begin{array}{c}-2,3620^{* * * *} \\
(0,465)\end{array}$ & $\begin{array}{l}-2,3625 \text { **** } \\
(0,464)\end{array}$ & $\begin{array}{c}-2,3497 * * * \\
(0,463)\end{array}$ & $\begin{array}{c}-2,3554^{* * * *} \\
(0,464)\end{array}$ & $\begin{array}{c}-2,3650 \text { **** } \\
(0,465)\end{array}$ & $\begin{array}{c}-2,3708^{* * * *} \\
(0,465)\end{array}$ \\
\hline TAM & $\begin{array}{l}0,2631 \text { *** } \\
(0,032)\end{array}$ & $\begin{array}{l}0,2637 \text { *** } \\
(0,032)\end{array}$ & $\begin{array}{l}0,2605 * * * \\
(0,032)\end{array}$ & $\begin{array}{l}0,2572 * * * \\
(0,032)\end{array}$ & $\begin{array}{l}0,2545^{* * * *} \\
(0,032)\end{array}$ & $\begin{array}{l}0,2524 * * * \\
(0,032)\end{array}$ \\
\hline OPCRESC & $\begin{array}{l}0,5170^{* * * *} \\
(0,061)\end{array}$ & $\begin{array}{l}0,5167 * * * * \\
(0,061)\end{array}$ & $\begin{array}{l}0,5031 \text { **** } \\
(0,061)\end{array}$ & $\begin{array}{l}0,4961 * * * \\
(0,060)\end{array}$ & $\begin{array}{l}0,4951 \text { *** } \\
(0,060)\end{array}$ & $\begin{array}{l}0,4921^{* * *} \\
(0,060)\end{array}$ \\
\hline ENDIV & $\begin{array}{c}-0,7416^{*} \\
(0,396)\end{array}$ & $\begin{array}{c}-0,7442 * \\
(0,396)\end{array}$ & $\begin{array}{c}-0,7199^{*} \\
(0,394)\end{array}$ & $\begin{array}{c}-0,7024^{*} \\
(0,393)\end{array}$ & $\begin{array}{c}-0,6947^{*} \\
(0,393)\end{array}$ & $\begin{array}{c}-0,6918^{*} \\
(0,392)\end{array}$ \\
\hline TANG & $\begin{array}{c}-0,6686^{* * *} \\
(0,217)\end{array}$ & $\begin{array}{c}-0,6698 * * * \\
(0,218)\end{array}$ & $\begin{array}{l}-0,6431^{* * *} \\
(0,217)\end{array}$ & $\begin{array}{c}-0,6294 * * * \\
(0,217)\end{array}$ & $\begin{array}{c}-0,6255^{* * *} * \\
(0,217)\end{array}$ & $\begin{array}{c}-0,6183^{* * * *} \\
(0,217)\end{array}$ \\
\hline n. obs. & 3110 & 3110 & 3110 & 3110 & 3110 & 3110 \\
\hline pseudo R2 & 0,103 & 0,103 & 0,103 & 0,104 & 0,105 & 0,105 \\
\hline Wald chi2(38) & 294,83 & 294,90 & 297,48 & 301,73 & 303,63 & 305,49 \\
\hline p-value & 0,000 & 0,000 & 0,000 & 0,000 & 0,000 & 0,000 \\
\hline
\end{tabular}

Notas: A variável dependente é a emissão de ação (EMI_AÇÃO). Variáveis independentes: acionista majoritário (ACMAJOR); concentração de propriedade nas mãos do principal acionista (CPROP1); concentração de propriedade nas mãos dos dois principais acionistas (CPROP2); concentração de propriedade nas mãos dos três principais acionistas (CPROP3); concentração de propriedade nas mãos dos quatro principais acionistas (CPROP4); concentração de propriedade nas mãos dos cinco principais acionistas (CPROP5); rentabilidade (ROA); tamanho (TAM); oportunidades de crescimento (OPCRESC); endividamento (ENDIV); tangibilidade (TANG). Foram estimados modelos logit. Coeficientes estimados e desvios padrões robustos à heteroscedasticidade (entre parênteses) referentes à estimação do modelo da equação (1). Modelos incluem dummies de país, setor e ano. ***, ** e * denotam significância estatística dos coeficientes em $1 \%, 5 \%$ e $10 \%$, respectivamente. 
Tabela 8

Estimação de modelos da emissão de ação no Peru

\begin{tabular}{|c|c|c|c|c|c|c|}
\hline variável & (i) & (ii) & (iii) & (iv) & (v) & (vi) \\
\hline ACMAJOR & $\begin{array}{r}0,0092 \\
(0,225)\end{array}$ & & & & & \\
\hline CPROP1 & & $\begin{array}{r}-0,2362 \\
(0,362)\end{array}$ & & & & \\
\hline CPROP2 & & & $\begin{array}{r}-0,5550 \\
(0,370)\end{array}$ & & & \\
\hline CPROP3 & & & & $\begin{array}{c}-0,9251^{* *} \\
(0,405)\end{array}$ & & \\
\hline CPROP4 & & & & & $\begin{array}{c}-1,1483^{\text {**** }} \\
(0,439)\end{array}$ & \\
\hline CPROP5 & & & & & & $\begin{array}{c}-1,2293^{* * * *} \\
(0,467)\end{array}$ \\
\hline ROA & $\begin{array}{c}-3,8596^{* * * *} \\
(1,287)\end{array}$ & $\begin{array}{c}-3,7680 \text { *** } \\
(1,296)\end{array}$ & $\begin{array}{c}-3,7133^{* * *} \\
(1,297)\end{array}$ & $\begin{array}{c}-3,6882^{* * * *} \\
(1,308)\end{array}$ & $\begin{array}{c}-3,6272 * * * * \\
(1,309)\end{array}$ & $\begin{array}{l}-3,589^{* * *} \\
(1,308)\end{array}$ \\
\hline TAM & $\begin{array}{l}0,1253 \\
(0,117)\end{array}$ & $\begin{array}{l}0,1171 \\
(0,117)\end{array}$ & $\begin{array}{l}0,0980 \\
(0,116)\end{array}$ & $\begin{array}{l}0,0766 \\
(0,116)\end{array}$ & $\begin{array}{l}0,0609 \\
(0,117)\end{array}$ & $\begin{array}{l}0,0524 \\
(0,117)\end{array}$ \\
\hline OPCRESC & $\begin{array}{l}0,3666^{* *} \\
(0,164)\end{array}$ & $\begin{array}{l}0,3526 * * \\
(0,165)\end{array}$ & $\begin{array}{l}0,3266^{* *} \\
(0,167)\end{array}$ & $\begin{array}{l}0,2999^{*} \\
(0,168)\end{array}$ & $\begin{array}{l}0,2851^{*} \\
(0,169)\end{array}$ & $\begin{array}{l}0,2819^{*} \\
(0,169)\end{array}$ \\
\hline ENDIV & $\begin{array}{l}1,3511 \\
(1,097)\end{array}$ & $\begin{array}{l}1,3806 \\
(1,082)\end{array}$ & $\begin{array}{r}1,3510 \\
(1,069)\end{array}$ & $\begin{array}{r}1,3135 \\
(1,0596)\end{array}$ & $\begin{array}{l}1,3106 \\
(1,057)\end{array}$ & $\begin{array}{l}1,3071 \\
(1,056)\end{array}$ \\
\hline TANG & $\begin{array}{c}-1,5734 * * \\
(0,678)\end{array}$ & $\begin{array}{c}-1,5087 * * \\
(0,675)\end{array}$ & $\begin{array}{c}-1,3937 * * \\
(0,677)\end{array}$ & $\begin{array}{c}-1,2642^{*} \\
(0,683)\end{array}$ & $\begin{array}{c}-1,2161 * \\
(0,685)\end{array}$ & $\begin{array}{c}-1,2339 * \\
(0,686)\end{array}$ \\
\hline n. obs. & 599 & 599 & 599 & 599 & 599 & 599 \\
\hline pseudo R2 & 0,220 & 0,220 & 0,223 & 0,226 & 0,228 & 0,229 \\
\hline Wald chi2(38) & 104,33 & 103,52 & 103,87 & 104,57 & 105,63 & 105,45 \\
\hline p-value & 0,000 & 0,000 & 0,000 & 0,000 & 0,000 & 0,000 \\
\hline
\end{tabular}

Notas: A variável dependente é a emissão de ação (EMI_AÇÃO). Variáveis independentes: acionista majoritário (ACMAJOR); concentração de propriedade nas mãos do principal acionista (CPROP1); concentração de propriedade nas mãos dos dois principais acionistas (CPROP2); concentração de propriedade nas mãos dos três principais acionistas (CPROP3); concentração de propriedade nas mãos dos quatro principais acionistas (CPROP4); concentração de propriedade nas mãos dos cinco principais acionistas (CPROP5); rentabilidade (ROA); tamanho (TAM); oportunidades de crescimento (OPCRESC); endividamento (ENDIV); tangibilidade (TANG). Foram estimados modelos logit. Coeficientes estimados e desvios padrões robustos à heteroscedasticidade (entre parênteses) referentes à estimação do modelo da equação (1). Modelos incluem dummies de país, setor e ano. ***, ** e * denotam significância estatística dos coeficientes em $1 \%, 5 \%$ e $10 \%$, respectivamente. 
Tabela 9

Estimação de modelos da emissão de ação no Chile

\begin{tabular}{|c|c|c|c|c|c|c|}
\hline variável & (i) & (ii) & (iii) & (iv) & (v) & (vi) \\
\hline ACMAJOR & $\begin{array}{c}-0,5429^{* *} \\
(0,241)\end{array}$ & & & & & \\
\hline CPROP1 & & $\begin{array}{c}-1,6569^{\text {**** }} \\
(0,634)\end{array}$ & & & & \\
\hline CPROP2 & & & $\begin{array}{c}-2,3393^{* * *} \\
(0,600)\end{array}$ & & & \\
\hline CPROP3 & & & & $\begin{array}{c}-2,4888^{* * * *} \\
(0,618)\end{array}$ & & \\
\hline CPROP4 & & & & & $\begin{array}{c}-2,6128 * * * * \\
(0,655)\end{array}$ & \\
\hline CPROP5 & & & & & & $\begin{array}{c}-2,7110^{* * * *} \\
(0,692)\end{array}$ \\
\hline ROA & $\begin{array}{c}-3,7279 \text { ** } \\
(1,779)\end{array}$ & $\begin{array}{c}-3,4844 * * \\
(1,775)\end{array}$ & $\begin{array}{c}-3,3710^{*} \\
(1,786)\end{array}$ & $\begin{array}{c}-3,4001^{*} \\
(1,805)\end{array}$ & $\begin{array}{c}-3,3562^{*} \\
(1,811)\end{array}$ & $\begin{array}{c}-3,3336^{*} \\
(1,813)\end{array}$ \\
\hline TAM & $\begin{array}{l}0,4272 * * * \\
(0,075)\end{array}$ & $\begin{array}{l}0,4025 * * * \\
(0,074)\end{array}$ & $\begin{array}{l}0,3944 * * * \\
(0,074)\end{array}$ & $\begin{array}{l}0,3861 * * * \\
(0,075)\end{array}$ & $\begin{array}{l}0,3782 \text { *** } \\
(0,075)\end{array}$ & $\begin{array}{l}0,3736^{* * *} \\
(0,075)\end{array}$ \\
\hline OPCRESC & $\begin{array}{l}0,3613^{*} \\
(0,204)\end{array}$ & $\begin{array}{l}0,3591^{*} \\
(0,206)\end{array}$ & $\begin{array}{l}0,3453^{*} \\
(0,198)\end{array}$ & $\begin{array}{l}0,3234 \\
(0,200)\end{array}$ & $\begin{array}{l}0,3120 \\
(0,201)\end{array}$ & $\begin{array}{l}0,3052 \\
(0,202)\end{array}$ \\
\hline ENDIV & $\begin{array}{r}0,0450 \\
(1,040)\end{array}$ & $\begin{array}{r}-0,2327 \\
(1,061)\end{array}$ & $\begin{array}{r}-0,5479 \\
(1,087)\end{array}$ & $\begin{array}{r}-0,5794 \\
(1,085)\end{array}$ & $\begin{array}{r}-0,5440 \\
(1,078)\end{array}$ & $\begin{array}{r}-0,5067 \\
(1,074)\end{array}$ \\
\hline TANG & $\begin{array}{c}-1,4536 * * \\
(0,636)\end{array}$ & $\begin{array}{c}-1,4925^{* *} \\
(0,630)\end{array}$ & $\begin{array}{c}-1,3661^{* *} \\
(0,619)\end{array}$ & $\begin{array}{c}-1,3191^{* *} \\
(0,619)\end{array}$ & $\begin{array}{c}-1,3377^{* *} \\
(0,616)\end{array}$ & $\begin{array}{c}-1,3576^{* *} \\
(0,615)\end{array}$ \\
\hline n. obs. & 622 & 622 & 622 & 622 & 622 & 622 \\
\hline pseudo R2 & 0,147 & 0,153 & 0,169 & 0,169 & 0,168 & 0,167 \\
\hline Wald chi2(27) & 72,65 & 75,30 & 78,91 & 78,70 & 77,60 & 76,92 \\
\hline p-value & 0,000 & 0,000 & 0,000 & 0,000 & 0,000 & 0,000 \\
\hline
\end{tabular}

Notas: A variável dependente é a emissão de ação (EMI_AÇÃO). Variáveis independentes: acionista majoritário (ACMAJOR); concentração de propriedade nas mãos do principal acionista (CPROP1); concentração de propriedade nas mãos dos dois principais acionistas (CPROP2); concentração de propriedade nas mãos dos três principais acionistas (CPROP3); concentração de propriedade nas mãos dos quatro principais acionistas (CPROP4); concentração de propriedade nas mãos dos cinco principais acionistas (CPROP5); rentabilidade (ROA); tamanho (TAM); oportunidades de crescimento (OPCRESC); endividamento (ENDIV); tangibilidade (TANG). Foram estimados modelos logit. Coeficientes estimados e desvios padrões robustos à heteroscedasticidade (entre parênteses) referentes à estimação do modelo da equação (1). Modelos incluem dummies de país, setor e ano. ***, ** e * denotam significância estatística dos coeficientes em $1 \%, 5 \%$ e $10 \%$, respectivamente. 
Tabela 10

Estimação de modelos da emissão de ação na Argentina

\begin{tabular}{|c|c|c|c|c|c|c|}
\hline variável & (i) & (ii) & (iii) & (iv) & (v) & (vi) \\
\hline ACMAJOR & $\begin{array}{r}-1,3552 \\
(2,052)\end{array}$ & & & & & \\
\hline CPROP1 & & $\begin{array}{r}0,5542 \\
(3,502)\end{array}$ & & & & \\
\hline CPROP2 & & & $\begin{array}{r}-0,3533 \\
(3,541)\end{array}$ & & & \\
\hline CPROP3 & & & & $\begin{array}{r}-0,7986 \\
(3,303)\end{array}$ & & \\
\hline CPROP4 & & & & & $\begin{array}{r}-0,7986 \\
(3,303)\end{array}$ & \\
\hline CPROP5 & & & & & & $\begin{array}{r}-0,7986 \\
(3,303)\end{array}$ \\
\hline ROA & $\begin{array}{r}-7,3936 \\
(5,425)\end{array}$ & $\begin{array}{r}-6,1906 \\
(5,336)\end{array}$ & $\begin{array}{r}-6,2608 \\
(5,211)\end{array}$ & $\begin{array}{r}-6,3271 \\
(5,150)\end{array}$ & $\begin{array}{r}-6,3271 \\
(5,150)\end{array}$ & $\begin{array}{r}-6,3271 \\
(5,145)\end{array}$ \\
\hline TAM & $\begin{array}{r}-0,8746 \\
(0,572)\end{array}$ & $\begin{array}{c}-1,0592 * \\
(0,583)\end{array}$ & $\begin{array}{c}-1,0279^{*} \\
(0,565)\end{array}$ & $\begin{array}{c}-1,0100^{*} \\
(0,551)\end{array}$ & $\begin{array}{c}-1,0100^{*} \\
(0,551)\end{array}$ & $\begin{array}{r}-1,0100 \\
(0,551)\end{array}$ \\
\hline OPCRESC & $\begin{array}{l}2,0325^{*} \\
(1,178)\end{array}$ & $\begin{array}{r}1,6365 \\
(1,275)\end{array}$ & $\begin{array}{l}1,7601 \\
(1,229)\end{array}$ & $\begin{array}{l}1,8405 \\
(1,224)\end{array}$ & $\begin{array}{l}1,8405 \\
(1,224)\end{array}$ & $\begin{array}{l}1,8405 \\
(1,224)\end{array}$ \\
\hline ENDIV & $\begin{array}{c}-6,1343^{*} \\
(3,331)\end{array}$ & $\begin{array}{c}-5,4387^{*} \\
(3,187)\end{array}$ & $\begin{array}{c}-5,4915^{*} \\
(3,094)\end{array}$ & $\begin{array}{c}-5,5617^{*} \\
(3,066)\end{array}$ & $\begin{array}{c}-5,5617^{*} \\
(3,066)\end{array}$ & $\begin{array}{r}-5,5617 \\
(3,066)\end{array}$ \\
\hline TANG & $\begin{array}{r}-2,2141 \\
(3,921)\end{array}$ & $\begin{array}{r}-0,8353 \\
(3,228)\end{array}$ & $\begin{array}{l}-1,143 \\
(3,341)\end{array}$ & $\begin{array}{r}-1,2491 \\
(3,148)\end{array}$ & $\begin{array}{r}-1,2491 \\
(3,148)\end{array}$ & $\begin{array}{r}-1,2491 \\
(3,148)\end{array}$ \\
\hline n. obs. & 84 & 84 & 84 & 84 & 84 & 84 \\
\hline pseudo R2 & 0,269 & 0,262 & 0,262 & 0,263 & 0,263 & 0,263 \\
\hline Wald chi2(18) & 30,65 & 28,35 & 29,29 & 29,83 & 29,83 & 26,29 \\
\hline p-value & 0,031 & 0,057 & 0,045 & 0,039 & 0,039 & 0,039 \\
\hline
\end{tabular}

Notas: A variável dependente é a emissão de ação (EMI_AÇÃO). Variáveis independentes: acionista majoritário (ACMAJOR); concentração de propriedade nas mãos do principal acionista (CPROP1); concentração de propriedade nas mãos dos dois principais acionistas (CPROP2); concentração de propriedade nas mãos dos três principais acionistas (CPROP3); concentração de propriedade nas mãos dos quatro principais acionistas (CPROP4); concentração de propriedade nas mãos dos cinco principais acionistas (CPROP5); rentabilidade (ROA); tamanho (TAM); oportunidades de crescimento (OPCRESC); endividamento (ENDIV); tangibilidade (TANG). Foram estimados modelos logit. Coeficientes estimados e desvios padrões robustos à heteroscedasticidade (entre parênteses) referentes à estimação do modelo da equação (1). Modelos incluem dummies de país, setor e ano. ***, ** $\mathrm{e} *$ denotam significância estatística dos coeficientes em $1 \%, 5 \%$ e $10 \%$, respectivamente. 
Tabela 11

Estimação de modelos da emissão de ação na Colômbia

\begin{tabular}{|c|c|c|c|c|c|c|}
\hline variável & (i) & (ii) & (iii) & (iv) & (v) & (vi) \\
\hline ACMAJOR & $\begin{array}{c}-2,8240^{* * *} \\
(1,263)\end{array}$ & & & & & \\
\hline CPROP1 & & $\begin{array}{r}-3,4241 \\
(2,502)\end{array}$ & & & & \\
\hline CPROP2 & & & $\begin{array}{r}-1,4216 \\
(1,508)\end{array}$ & & & \\
\hline CPROP3 & & & & $\begin{array}{r}-0,7101 \\
(1,462)\end{array}$ & & \\
\hline CPROP4 & & & & & $\begin{array}{r}-0,3128 \\
(1,494)\end{array}$ & \\
\hline CPROP5 & & & & & & $\begin{array}{l}-0,5282 \\
(1,5424)\end{array}$ \\
\hline ROA & $\begin{array}{l}3,5737 \\
(6,157)\end{array}$ & $\begin{array}{l}3,2426 \\
(6,267)\end{array}$ & $\begin{array}{l}3,0655 \\
(6,305)\end{array}$ & $\begin{array}{l}2,1664 \\
(6,240)\end{array}$ & $\begin{array}{l}1,7452 \\
(6,188)\end{array}$ & $\begin{array}{l}1,8939 \\
(6,217)\end{array}$ \\
\hline TAM & $\begin{array}{l}0,4419 \\
(0,469)\end{array}$ & $\begin{array}{l}0,2699 \\
(0,461)\end{array}$ & $\begin{array}{l}0,0835 \\
(0,384)\end{array}$ & $\begin{array}{r}0,0249 \\
(0,362)\end{array}$ & $\begin{array}{r}0,0027 \\
(0,356)\end{array}$ & $\begin{array}{l}0,0088 \\
(0,354)\end{array}$ \\
\hline OPCRESC & $\begin{array}{l}1,5649^{* *} * \\
(0,642)\end{array}$ & $\begin{array}{l}1,1221^{*} \\
(0,634)\end{array}$ & $\begin{array}{l}1,0231^{*} \\
(0,590)\end{array}$ & $\begin{array}{l}1,0218^{*} \\
(0,589)\end{array}$ & $\begin{array}{l}1,0212^{*} \\
(0,591)\end{array}$ & $\begin{array}{l}1,0204 \\
(0,588)\end{array}$ \\
\hline ENDIV & $\begin{array}{r}5,8223 \\
(3,824)\end{array}$ & $\begin{array}{l}6,6174 * \\
(3,489)\end{array}$ & $\begin{array}{l}5,8989^{*} \\
(3,591)\end{array}$ & $\begin{array}{l}5,6975 \\
(3,537)\end{array}$ & $\begin{array}{l}5,5431 \\
(3,496)\end{array}$ & $\begin{array}{l}5,6542 \\
(3,541)\end{array}$ \\
\hline TANG & $\begin{array}{r}1,6993 \\
(2,676)\end{array}$ & $\begin{array}{l}1,3779 \\
(2,664)\end{array}$ & $\begin{array}{l}1,5005 \\
(2,510)\end{array}$ & $\begin{array}{l}1,4721 \\
(2,477)\end{array}$ & $\begin{array}{l}1,4250 \\
(2,467)\end{array}$ & $\begin{array}{l}1,4422 \\
(2,459)\end{array}$ \\
\hline $\begin{array}{l}\text { n. obs. } \\
\text { pseudo R2 }\end{array}$ & $\begin{array}{r}138 \\
0,415\end{array}$ & $\begin{array}{r}138 \\
0,404\end{array}$ & $\begin{array}{r}138 \\
0,396\end{array}$ & $\begin{array}{r}138 \\
0,393\end{array}$ & $\begin{array}{r}138 \\
0,393\end{array}$ & $\begin{array}{r}138 \\
0,393\end{array}$ \\
\hline Wald chi2(28) & - & - & - & - & - & - \\
\hline $\mathrm{p}$-value & - & - & - & - & - & - \\
\hline
\end{tabular}

Notas: A variável dependente é a emissão de ação (EMI_AÇÃO). Variáveis independentes: acionista majoritário (ACMAJOR); concentração de propriedade nas mãos do principal acionista (CPROP1); concentração de propriedade nas mãos dos dois principais acionistas (CPROP2); concentração de propriedade nas mãos dos três principais acionistas (CPROP3); concentração de propriedade nas mãos dos quatro principais acionistas (CPROP4); concentração de propriedade nas mãos dos cinco principais acionistas (CPROP5); rentabilidade (ROA); tamanho (TAM); oportunidades de crescimento (OPCRESC); endividamento (ENDIV); tangibilidade (TANG). Foram estimados modelos logit. Coeficientes estimados e desvios padrões robustos à heteroscedasticidade (entre parênteses) referentes à estimação do modelo da equação (1). Modelos incluem dummies de país, setor e ano. ***, ** $\mathrm{e} *$ denotam significância estatística dos coeficientes em $1 \%, 5 \%$ e $10 \%$, respectivamente. 
Tabela 12

Estimação de modelos da emissão de ação no México

\begin{tabular}{|c|c|c|c|c|c|c|}
\hline variável & (i) & (ii) & (iii) & (iv) & (v) & (vi) \\
\hline ACMAJOR & $\begin{array}{l}0,2976 \\
(0,527)\end{array}$ & & & & & \\
\hline CPROP1 & & $\begin{array}{l}0,9883 \\
(1,099)\end{array}$ & & & & \\
\hline CPROP2 & & & $\begin{array}{l}0,3891 \\
(1,144)\end{array}$ & & & \\
\hline CPROP3 & & & & $\begin{array}{r}0,2267 \\
(1,179)\end{array}$ & & \\
\hline CPROP4 & & & & & $\begin{array}{l}0,2065 \\
(1,237)\end{array}$ & \\
\hline CPROP5 & & & & & & $\begin{array}{r}0,1484 \\
(1,2778)\end{array}$ \\
\hline ROA & $\begin{array}{r}-1,1544 \\
(1,823)\end{array}$ & $\begin{array}{r}-1,2178 \\
(1,729)\end{array}$ & $\begin{array}{r}-0,9269 \\
(1,703)\end{array}$ & $\begin{array}{r}-0,8693 \\
(1,709)\end{array}$ & $\begin{array}{r}-0,8641 \\
(1,716)\end{array}$ & $\begin{array}{r}-0,8472 \\
(1,727)\end{array}$ \\
\hline TAM & $\begin{array}{r}-0,1044 \\
(0,186)\end{array}$ & $\begin{array}{r}-0,1184 \\
(0,180)\end{array}$ & $\begin{array}{r}-0,1221 \\
(0,179)\end{array}$ & $\begin{array}{r}-0,1193 \\
(0,179)\end{array}$ & $\begin{array}{r}-0,1189 \\
(0,179)\end{array}$ & $\begin{array}{r}-0,1176 \\
(0,179)\end{array}$ \\
\hline OPCRESC & $\begin{array}{r}-1,1313 \\
(0,695)\end{array}$ & $\begin{array}{c}-1,1789^{*} \\
(0,711)\end{array}$ & $\begin{array}{c}-1,1577 * \\
(0,694)\end{array}$ & $\begin{array}{c}-1,1526^{*} \\
(0,689)\end{array}$ & $\begin{array}{c}-1,1529 * \\
(0,689)\end{array}$ & $\begin{array}{r}-1,1517 \\
(0,689)\end{array}$ \\
\hline ENDIV & $\begin{array}{r}1,3539 \\
(1,920)\end{array}$ & $\begin{array}{l}1,5486 \\
(1,946)\end{array}$ & $\begin{array}{r}1,5442 \\
(1,931)\end{array}$ & $\begin{array}{l}1,5404 \\
(1,923)\end{array}$ & $\begin{array}{l}1,5375 \\
(1,921)\end{array}$ & $\begin{array}{r}1,5338 \\
(1,923)\end{array}$ \\
\hline TANG & $\begin{array}{r}-1,8265 \\
(1,369)\end{array}$ & $\begin{array}{r}-1,7799 \\
(1,396)\end{array}$ & $\begin{array}{r}-1,8353 \\
(1,397)\end{array}$ & $\begin{array}{r}-1,8344 \\
(1,398)\end{array}$ & $\begin{array}{r}-1,8371 \\
(1,405)\end{array}$ & $\begin{array}{r}-1,8339 \\
(1,409)\end{array}$ \\
\hline n. obs. & 179 & 179 & 179 & 179 & 179 & 179 \\
\hline pseudo R2 & 0,180 & 0,184 & 0,179 & 0,178 & 0,178 & 0,178 \\
\hline Wald chi2(28) & 26,69 & 26,89 & 27,17 & 27,31 & 27,38 & 27,49 \\
\hline p-value & 0,045 & 0,042 & 0,039 & 0,038 & 0,037 & 0,036 \\
\hline
\end{tabular}

Notas: A variável dependente é a emissão de ação (EMI_AÇÁO). Variáveis independentes: acionista majoritário (ACMAJOR); concentração de propriedade nas mãos do principal acionista (CPROP1); concentração de propriedade nas mãos dos dois principais acionistas (CPROP2); concentração de propriedade nas mãos dos três principais acionistas (CPROP3); concentração de propriedade nas mãos dos quatro principais acionistas (CPROP4); concentração de propriedade nas mãos dos cinco principais acionistas (CPROP5); rentabilidade (ROA); tamanho (TAM); oportunidades de crescimento (OPCRESC); endividamento (ENDIV); tangibilidade (TANG). Foram estimados modelos logit. Coeficientes estimados e desvios padrões robustos à heteroscedasticidade (entre parênteses) referentes à estimação do modelo da equação (1). Modelos incluem dummies de país, setor e ano. ***, ** e * denotam significância estatística dos coeficientes em $1 \%, 5 \%$ e $10 \%$, respectivamente.

emissão de ações o que pode ser explicado por poucos projetos de investimento que seriam supridos plenamente pela disponibilidade de fluxo de caixa e capacidade de captação de dívida.

Estes resultados individualizados por país indicam que, de fato, parece haver fatores típicos de cada ambiente legal e institucional que são capazes de influenciar a capacidade de financiamento destas empresas através de emissão de ação. Tais fatores estão relacionados a conflitos de agência que fazem com que a concentração de propriedade sobre a decisão de financiamento por 
emissão de ação apresente efeito distinto entre os países. Este efeito tende a ser muito negativo no Brasil, Peru, Chile e um pouco em Colômbia, enquanto é inexistente na Argentina e México. De modo similar, há também um efeito claramente adverso do endividamento sobre a probabilidade de emissão de ação no Brasil e Argentina, enquanto este efeito inexiste nos demais países.

\subsection{Análise de sensibilidade e resultados adicionais}

Como mencionado anteriormente, modelos alternativos foram estimados de modo obter-se robustez de resultados como também deixar algumas questões mais claras. Neste sentido, todos os modelos apresentados foram estimados em algumas versões alternativas, confirmando-se os resultados exibidos. Foram estimados somente com o endividamento e, também, somente com a tangibilidade dos ativos. Em todos os modelos estimados, confirmou-se a influência negativa da concentração de propriedade sobre a propensão da empresa a emitir ação na América Latina. Estas estimações alternativas confirmaram a correlação negativa da disponibilidade de ativos tangíveis sobre a probabilidade de emissão de ação sendo um sinal que esta disponibilidade de ativos tangíveis para uso como garantia pode estimular a utilização de dívida e desestimular a emissão de ações. Especificamente sobre o endividamento, modelos específicos de endividamento, estimados por mínimos quadrados ordinários foram também estimados. Como esperado, estes mostraram um forte efeito positivo da tangibilidade sobre o endividamento da empresa latino-americana.

Os modelos (equação 1) foram estimados separadamente para sub amostras considerando a possibilidade de mudança de comportamento de grandes acionistas frente a distintos cenários de oportunidades de crescimento ou de rentabilidade da empresa. Esta argumentação advinda do contexto de agência sugere a utilização de dívida como instrumento de monitoração da direção da empresa uma vez que fluxo de caixa comprometido com pagamento de dívida evita problemas de fluxo de caixa livre (Jensen; 1986; López-Iturriaga and Crisóstomo; 2010). Relativamente à emissão de ação seria plausível esperarse que em cenários de mais oportunidades de crescimento, grandes acionistas estariam mais propensos a aceitar emissão de ação para aproveitar todas as oportunidades de investimento disponíveis. Ao contrário, frente a menos oportunidades de crescimento, grandes acionistas seriam mais resistentes ainda a emitir ação, aproveitando o uso da dívida como instrumento de limitação de fluxo de caixa livre. Entretanto, os resultados para ambos os grupos de empresas, com e sem oportunidades de crescimento, são qualitativamente os mesmos, indicando a grande dificuldade de emissão de ação nestes mercados gerada pela concentração de propriedade, seja devido ao receio de perda de 
controle, podendo também estar amparado na proposta de agência de uso da dívida como instrumento de monitoração executiva. A mais baixa rentabilidade também poderia ser um fator que favorecesse a emissão de ação já que a empresa contaria com menos fluxo de caixa para honrar compromisso de dívida. No entanto, também não há mudança no efeito negativo da concentração de propriedade sobre a probabilidade de emissão de ação entre empresas mais ou menos rentáveis. Os modelos mencionados estão disponíveis em um apêndice a este artigo.

\section{Conclusões}

Este trabalho teve como objetivo identificar o efeito da concentração de propriedade sobre a propensão a emitir ação da empresa latino-americana analisando empresas não financeiras listadas nas bolsas de valores da Argentina, Brasil, Chile, Colômbia, México e Peru. O grande mercado consumidor destes países, aliado à crescente visibilidade dos mesmos, faz deste um estudo relevante uma vez que pouco se há pesquisado sobre comportamento emissor de ação nestes mercados emergentes.

Os resultados sinalizam que a concentração de propriedade é um fator que restringe a emissão de ação de empresas latino-americanas, indicando um possível receio de perda de controle por grandes acionistas, como também uma dificuldade de captação por emissão de ação nestes mercados nos quais acionistas minoritários são ainda pouco protegidos e podem ter receio de sofrerem expropriação por parte de acionistas majoritários.

Verificou-se que a rentabilidade está negativamente associada à emissão de ação na empresa latino-americana. Este resultado é uma indicação de que a empresa latino-americana estaria seguindo um comportamento pecking order ao usar fluxo de caixa gerado pelo mais alto lucro para financiar o investimento. Cabe mencionar a influência positiva do tamanho da empresa latinoamericana na sua propensão a emitir ação. Esta influência está de acordo com as proposições teóricas relacionadas à reputação corporativa, histórico de mercado de grandes empresas, disponibilidade de garantias (collateral) e diversificação do negócio que diminuirá o risco de falência. De fato, as empresas latino-americanas de menor porte enfrentam mais dificuldade para acessar esta fonte de financiamento. Os resultados indicam que as oportunidades de crescimento das empresas de países da América Latina impulsionam a emissão de ação, como esperado. Empresas com bons projetos de investimento estariam esgotando sua disponibilidade de fluxo de caixa e endividamento e também sendo capazes de captar financiamento através da emissão de ação em comportamento tipicamente pecking order, ou, então se pode entender que a boa qualidade destes projetos já as habilitam diretamente a emitir 
ação. Contrariamente ao esperado, não observou-se efeito negativo do endividamento sobre a emissão de ação, havendo sim uma insensibilidade entre as duas fontes de financiamento. A confirmação do efeito negativo do grau de disponibilidade de ativos tangíveis sobre a propensão à emissão de ação indica que esta tangibilidade de ativos está, de fato, favorecendo o financiamento através de dívida. Outro achado que merece menção é a diferença de resultados encontrados em cada país isoladamente. Esta distinção de resultados indica que parece haver, de fato, fatores específicos de cada entorno legal e institucional que são capazes de interferir na capacidade captação de recursos da empresa através de emissão de ação.

Considera-se que esta pesquisa contribui para o debate sobre o tema estrutura de capital ao prover evidência adicional sobre a empresa da América Latina que é uma região que apresenta um ambiente institucional semelhante entre os países, contando com mercados de capitais ainda pouco desenvolvidos, e que tem passado por mudanças políticas, econômicas e sociais nas últimas décadas. O coletivo destas empresas parece tender a seguir um comportamento pecking order que sugere que se prioriza a utilização de fluxo de caixa decorrente da rentabilidade para financiar investimento. A emissão de ação como opção de financiamento é mais usada por empresas de maior porte e aquelas com mais oportunidades de crescimento. Por outro lado, a emissão de ação parece ser uma opção de financiamento pouco atrativa para empresas com alta concentração de propriedade. O efeito concentração de propriedade destaca o problema de agência nestes mercados nos quais pequenos investidores parecem resistir ao investimento em ações ao mesmo tempo em que acionistas controladores podem ter receio da perda de controle sobre a empresa.

Algumas contribuições do trabalho merecem menção. $\mathrm{O}$ artigo aprofunda a pesquisa sobre a decisão de financiamento na América Latina, importante coletivo de países em desenvolvimento com características comuns, mas também com idiossincrasias. A decisão sobre a emissão de ação é ainda muito pouco explorada pela academia nestes países. A decisão de financiamento através de emissão de ação é analisada sob o enfoque de agência ao levar em conta o papel exercido pela concentração de propriedade neste processo. A decisão de emissão de ação é também observada sob a óptica da Teoria Pecking Order ao considerar-se a influência da rentabilidade além de outros fatores apontados como pertinentes para decisões sobre financiamento.

Por fim, além do interesse acadêmico, os resultados do trabalho podem também ser de interesse para a articulação de recomendações de políticas relativas ao processo de financiamento do investimento, a nível micro e macro econômico, no sentido de entender-se melhor o processo de emissão de ação 
na América Latina que é importante forma de financiamento.

\section{Referências}

Ahmed, K. and Courtis, J. K. (1999). Associations between corporate characteristics and disclosure levels in annual reports: A meta-analysis, British Accounting Review 31(1): 35 - 61.

URL: http: / /www. sciencedirect.com/science/article/ pii/s0890838998900828

Akerlof, G. A. (1970). The Market for "Lemons": Quality Uncertainty and the Market Mechanism, Quarterly Journal of Economics 84(3): 488-500.

URL: https : / /doi .org/10.2307/1879431

Albanez, T. and Valle, M. R. d. (2009). Impactos da assimetria de informação na estrutura de capital de empresas brasileiras abertas, Revista Contabilidade \& Finanças 20: 6 - 27.

URL: http: / / www.scielo.br/scielo.php?script=sci_a rttext\&pid=S1519-70772009000300002\&nrm=iso

Asquith, P. and Mullins, D. W. (1986). Equity issues and offering dilution, Journal of Financial Economics 15(1): 61 - 89.

URL: http: / / www. sciencedirect.com/science/article/ pii/0304405X86900504

Baker, M., Stein, J. C. and Wurgler, J. (2003). When does the market matter? Stock prices and the investment of equity-dependent firms, Quarterly Journal of Economics 118(3): 969-1005.

URL: https : / /doi .org/10.1162/00335530360698478

Barclay, M. J. and Smith, C. W. (2005). The capital structure puzzle: The evidence revisited, Journal of Applied Corporate Finance 17(1): 8-17.

URL: https : / / onlinelibrary .wiley . com/doi/abs / 10 . 1 $111 / j .1745-6622.2005 .012 \_2 . x$

Bastos, D. D. and Nakamura, W. T. (2009). Determinantes da estrutura de capital das companhias abertas no Brasil, México e Chile no período 20012006, Revista Contabilidade \& Finanças 20: 75 - 94.

URL: http: / / www.scielo.br/scielo.php?script=sci_a rttext\&pid=S1519-70772009000200006\&nrm=iso

Bastos, D. D., Nakamura, W. T. and Basso, L. F. C. (2009). Determinantes da estrutura de capital das companhias abertas na América Latina: Um estudo 
empírico considerando fatores macroeconômicos e institucionais, Revista de Administração Mackenzie 10(6): 47 - 77.

URL: http: / /www.scielo.br/scielo.php?script=sci_a rttext\&pid=S1678-69712009000600005\&nrm=iso

Beck, T. and Levine, R. (2002). Industry growth and capital allocation: Does having a market- or bank-based system matter?, Journal of Financial Economics 64(2): 147 - 180.

URL: http: //www.sciencedirect.com/science/article/ pii/s0304405X02000740

Beck, T., Levine, R. and Loayza, N. (2000). Finance and the sources of growth, Journal of Financial Economics 58(1): 261 - 300. Special Issue on International Corporate Governance.

URL: http: //www.sciencedirect.com/science/article/ pii/s0304405X00000726

Bevan, A. A. and Danbolt, J. (2002). Capital structure and its determinants in the uk - A decompositional analysis, Applied Financial Economics 12(3): 159-170.

URL: https: //doi.org/10.1080/09603100110090073

Boadi, I., Osarfo, D. and Boadi, P. (2019). Bank-based and market-based development and economic growth: An international investigation, Studies in Economics and Finance 36(3): 365-394.

URL: https://doi .org/10.1108/SEF-12-2017-0346

Bogéa Sobrinho, L. R., Sheng, H. H. and Lora, M. I. (2012). Country factors and dynamic capital structure in Latin American firms, Brazilian Review of Finance 10(2): 267-284.

URL: http: //bibliotecadigital.fgv.br/ojs/index.php /rbfin/article/view/3623

Bokpin, G. A. and Arko, A. C. (2009). Ownership structure, corporate governance and capital structure decisions of firms: Empirical evidence from Ghana, Studies in Economics and Finance 26(4): 246-256.

URL: https: //doi.org/10.1108/10867370910995708

Bond, S. R. and Meghir, C. (1994). Financial constraints and company investment, Fiscal Studies 15(2): 1-18.

Borda, A., Geleilate, J.-M. G., Newburry, W. and Kundu, S. K. (2017). Firm internationalization, business group diversification and firm performance: 
The case of Latin American firms, Journal of Business Research 72: 104 113.

URL: http: //www.sciencedirect.com/science/article/ pii/s0148296316306233

Brailsford, T. J., Oliver, B. R. and Pua, S. L. H. (2002). On the relation between ownership structure and capital structure, Accounting \& Finance 42(1): 1-26.

URL: https://onlinelibrary.wiley.com/doi/abs/10.1 111/1467-629x.00001

Brito, G. A. S., Corrar, L. J. and Batistella, F. D. (2007). Fatores determinantes da estrutura de capital das maiores empresas que atuam no Brasil, Revista Contabilidade \& Finanças 18: 9 - 19.

URL: http: //www.scielo.br/scielo.php?script=sci_a rttext\&pid=S1519-70772007000100002\&nrm=iso

Carneiro, J. and Brenes, E. R. (2014). Latin American firms competing in the global economy, Journal of Business Research 67(5): 831 - 836.

URL: http: //www.sciencedirect.com/science/article/ pii/S014829631300266X

Céspedes, J., González, M. and Molina, C. A. (2010). Ownership and capital structure in Latin America, Journal of Business Research 63(3): 248 - 254. URL: http: / /www.sciencedirect.com/science/article/ pii/s014829630900068X

Chen, J. J. (2004). Determinants of capital structure of Chinese-listed companies, Journal of Business Research 57(12): 1341 - 1351. Mobility and Markets: Emerging Outlines of M-Commerce.

URL: http: //www.sciencedirect.com/science/article/ pii/s0148296303000705

Cheung, A. W. K. (2016). Corporate social responsibility and corporate cash holdings, Journal of Corporate Finance 37: 412 - 430.

URL: http: //www.sciencedirect.com/science/article/ pii/s0929119916000092

Claessens, S., Djankov, S. and Lang, L. H. (2000). The separation of ownership and control in East Asian corporations, Journal of Financial Economics 58(1): 81 - 112. Special Issue on International Corporate Governance. 
URL: http: / /www.sciencedirect.com/science/article/ pii/s0304405X00000672

Correa, C. A., Basso, L. F. C. and Nakamura, W. T. (2013). A estrutura de capital das maiores empresas brasileiras: Análise empírica das teorias de pecking order e trade-off usando panel data, Revista de Administração Mackenzie 14(4): 106 - 133.

URL: http: //www.scielo.br/scielo.php?script=sci_a rttext\&pid=S1678-69712013000400005\&nrm=iso

Crisóstomo, V. L. and Brandão, I. F. (2019). The ultimate controlling owner and corporate governance in Brazil, Corporate Governance: The International Journal of Business in Society 19(1): 120-140.

URL: https : / /oi .org/10.1108/CG-01-2018-0043

Crisóstomo, V. L. and Pinheiro, B. G. (2015). Estrutura de capital e concentração de propriedade da empresa brasileira, Revista de Finanças Aplicadas 2015(4): 1-30.

Cuervo-Cazurra, A. (2008). The multinationalization of developing country MNEs: The case of multilatinas, Journal of International Management 14(2): $138-154$.

URL: http: / /www.sciencedirect.com/science/article/ $\mathrm{pii/S1075425308000288}$

de Haan, L. and Hinloopen, J. (2003). Preference hierarchies for internal finance, bank loans, bond, and share issues: Evidence for Dutch firms, Journal of Empirical Finance 10(5): 661 - 681.

URL: http: / /www.sciencedirect.com/science/article/ pii/s0927539803000100

Driffield, N., Mahambare, V. and Pal, S. (2007). How does ownership structure affect capital structure and firm value? Recent evidence from East Asia, Economics of Transition and Institutional Change 15(3): 535-573.

URL: https://onlinelibrary.wiley.com/doi/abs/10.1 111/j.1468-0351.2007.00291.x

Dyck, A. and Zingales, L. (2004). Private benefits of control: An international comparison, Journal of Finance 59(2): 537-600.

URL: https: / /onlinelibrary.wiley.com/doi/abs/10 . 1 $111 / j .1540-6261.2004 .00642 . x$

Eid Júnior, W. (1996). Custo e estrutura de capital: O comportamento das empresas brasileiras, Revista de Administração de Empresas 36(4): 51-59. 
Fávero, L. P., Belfione, P., Silva, F. L. and Chan, B. L. (2009). Análise de Dados: Modelagem Multivariada para Tomada de Decisões, Elsevier, Rio de Janeiro.

Ganguli, S. K. (2013). Capital structure - does ownership structure matter? Theory and Indian evidence, Studies in Economics and Finance 30(1): 5672.

URL: https://doi.org/10.1108/10867371311300982

Gonenc, H. and Hermes, N. (2008). Propping: Evidence from new share issues of Turkish business group firms, Journal of Multinational Financial Management 18(3): $261-275$.

URL: http: //www.sciencedirect.com/science/article/ pii/S1042444X07000588

Hair, J. F., Black, W. C., Babin, B. J., Anderson, R. E. and Tatham, R. L. (2009). Análise Multivariada de Dados, 6 edn, Bookman, Porto Alegre.

Haron, R. (2014). Capital structure inconclusiveness: Evidence from Malaysia, Thailand and Singapore, International Journal of Managerial Finance 10(1): 23-38.

URL: https : / doi .org/10.1108/IJMF-03-2012-0025

Harris, M. and Raviv, A. (1991). The theory of capital structure, The Journal of Finance 46(1): 297-355.

URL: https : / / onlinelibrary.wiley.com/doi/abs/10.1 111/j.1540-6261.1991.tb03753.x

Jensen, M. C. (1986). Agency costs of free cash flow, corporate finance, and takeovers, American Economic Review 76(2): 323-329.

La Porta, R., de Silanes, F. L., Shleifer, A. and Vishny, R. (1998). Law and finance, Journal of Political Economy 106(6): 1113-1155.

La Porta, R., de Silanes, F. L., Shleifer, A. and Vishny, R. (2000). Investor protection and corporate governance, Journal of Financial Economics 58(1): 3 - 27. Special Issue on International Corporate Governance.

URL: http: //www.sciencedirect.com/science/article/ pii/s0304405X00000659

La Porta, R., Lopez-de-Silanes, F. and Shleifer, A. (1999). Corporate ownership around the world, Journal of Finance 54(2): 471-517.

URL: https://onlinelibrary.wiley.com/doi/abs/10 . 1 111/0022-1082.00115 
La Porta, R., Lopez-de-Silanes, F., Shleifer, A. and Vishny, R. W. (1997). Legal determinants of external finance, Journal of Finance 52(3): 11311150 .

URL: https : / /onlinelibrary.wiley.com/doi/abs/10 .1 111/j.1540-6261.1997.tb02727.x

López-Iturriaga, F. J. and Crisóstomo, V. L. (2010). Do leverage, dividend payout, and ownership concentration influence firms' value creation? An analysis of Brazilian firms, Emerging Markets Finance and Trade 46(3): 80-94.

URL: https://doi .org/10.2753/REE1540-496X460306

Medeiros, O. R. and Daher, C. E. (2008). Testando teorias alternativas sobre a estrutura de capital nas empresas brasileiras, Revista de Administração Contemporânea 12: 177 - 199.

URL: http: / /www.scielo.br/scielo.php?script=sci_a rttext\&pid=S1415-65552008000100009\&nrm=iso

Mendes, E. A., Basso, L. F. C. and Kayo, E. K. (2009). Estrutura de capital e janelas de oportunidade: Testes no mercado brasileiro, Revista de Administração Mackenzie 10(6): 78 - 100.

Mikkelson, W. H. and Partch, M. M. (1986). Valuation effects of security offerings and the issuance process, Journal of Financial Economics 15(1): 31 -60 .

URL: http: / /www.sciencedirect.com/science/article/ pii/0304405X86900498

Modigliani, F. and Miller, M. H. (1958). The cost of capital, corporation finance and theory of investment, American Economic Review 48(3): 261 $-297$.

Morck, R., Shleifer, A. and Vishny, R. W. (1988). Management ownership and market valuation: An empirical analysis, Journal of Financial Economics 20: 293 - 315. The Distribution of Power Among Corporate Managers, Shareholders, and Directors.

URL: http: //www.sciencedirect.com/science/article/ pii/0304405X88900487

Myers, S. C. (1977). Determinants of corporate borrowing, Journal of Financial Economics 5(2): 147 - 175.

URL: http: //www.sciencedirect.com/science/article/ pii/0304405X77900150 
Myers, S. C. (1984). The capital structure puzzle, Journal of Finance 39(3): 574-592.

URL: https://onlinelibrary.wiley.com/doi/abs/10 . 1 111/j.1540-6261.1984.tb03646.x

Myers, S. C. (2003). Financing of corporations, in G. M. Constantinides, M. Harris and R. M. Stulz (eds), Handbook of the Economics of Finance, Elsevier, North-Holland, Amsterdam, pp. 215-253.

Myers, S. C. and Majluf, N. S. (1984). Corporate financing and investment decisions when firms have information that investors do not have, Journal of Financial Economics 13(2): 187 - 221.

URL: http: / /www.sciencedirect.com/science/article/ pii/0304405X84900230

Oliveira, B. C. and Kayo, E. K. (2015). Desempenho de ações de empresas brasileiras após seu IPO: Evidências de curto e de longo prazo, Revista de Gestão USP 22(2): 173-186.

Oliveira, B. C. and Martelanc, R. (2014). IPO determinants of Brazilian companies, Brazilian Review of Finance 12(2): 135-161.

Rajan, R. G. and Zingales, L. (1995). What do we know about capital structure? Some evidence from international data, Journal of Finance 50(5): 1421-1460.

URL: https://onlinelibrary.wiley.com/doi/abs/10 1 111/j.1540-6261.1995.tb05184.x

Ross, S. A. (1977). The determination of financial structure: The incentivesignalling approach, Bell Journal of Economics 8(1): 23-40.

URL: http: / /www. jstor.org/stable/3003485

Salzmann, A. and Soypak, K. (2017). National culture and private benefits of control, Finance Research Letters 20: 199 - 206.

URL: http: / /www.sciencedirect.com/science/article/ pii/s1544612316301829

Santiago-Castro, M. and Brown, C. J. (2007). Ownership structure and minority rights: A Latin American view, Journal of Economics and Business 59(5): 430 - 442. Ownership structure and corporate decision-making.

URL: http: //www.sciencedirect.com/science/article/ pii/s0148619507000409 
Saona, P. and San Martín, P. (2016). Country level governance variables and ownership concentration as determinants of firm value in Latin America, International Review of Law and Economics 47: 84 - 95.

URL: http: //www.sciencedirect.com/science/article/ pii/s0144818816300308

Shyam-Sunder, L. and Myers, S. C. (1999). Testing static tradeoff against pecking order models of capital structure, Journal of Financial Economics 51(2): $219-244$.

URL: http: / /www.sciencedirect.com/science/article/ pii/s0304405X98000518

Stein, J. C. (2003). Agency, information, and corporate investment, in G. M. Constantinides, M. Harris and R. M. Stulz (eds), Handbook of the Economics of Finance, Elsevier, North-Holland, Amsterdam, pp. 111-165.

Stulz, R. M. (1990). Managerial discretion and optimal financing policies, Journal of Financial Economics 26(1): 3 - 27.

URL: http: //www.sciencedirect.com/science/article/ pii/0304405X9090011N

Terra, P. R. S. (2007). Estrutura de capital e fatores macroeconômicos na América Latina, RAUSP Management Journal 42(2): 192-204.

Terra, P. R. S. (2009). Are leverage and debt maturity complements or substitutes? Evidence from Latin America, Revista de Administração Mackenzie 10(6): $4-24$.

URL: http: / /www.scielo.br/scielo.php?script=sci_a rttext\&pid=S1678-69712009000600003\&nrm=iso

Titman, S. and Wessels, R. (1988). The determinants of capital structure choice, Journal of Finance 43(1): 1-19.

URL: https://onlinelibrary.wiley.com/doi/abs/10.1 $111 / j .1540-6261.1988 \cdot t b 02585 . x$

Wurgler, J. (2000). Financial markets and the allocation of capital, Journal of Financial Economics 58(1): 187 - 214. Special Issue on International Corporate Governance.

URL: http: / /www.sciencedirect.com/science/article/ pii/s0304405X00000702

Young, M. N., Peng, M. W., Ahlstrom, D., Bruton, G. D. and Jiang, Y. (2008). Corporate governance in emerging economies: A review of the principalprincipal perspective, Journal of Management Studies 45(1): 196-220. 
URL: https://onlinelibrary.wiley.com/doi/abs/10.1 $111 / j .1467-6486.2007 .00752 . x$ 


\section{A. Análise de sensibilidade e resultados adicionais}

Como mencionado na seção 4.3, modelos alternativos foram estimados de modo obter-se robustez de resultados como também visando elucidar melhor algumas questões. Com este intuito, os modelos apresentados na Tabela 6 correspondentes à equação (1) foram estimados em algumas versões alternativas, confirmando-se os resultados ali exibidos. Considerando o possível efeito da tangibilidade de ativos sobre o endividamento, os modelos foram estimados com a presença destas variáveis separadamente. Modelos que contêm endividamento como variável explicativa e excluem a tangibilidade são exibidos na Tabela A1. E modelos que contemplam a variável tangibilidade excluindo-se o endividamento são apresentados na Tabela A2. Em todos os modelos adicionais estimados, confirmou-se a influência negativa da concentração de propriedade sobre a propensão da empresa a emitir ação na América Latina.

Além de confirmar o efeito negativo da concentração de propriedade, estas estimações alternativas confirmaram a correlação negativa da disponibilidade de ativos tangíveis sobre a probabilidade de emissão de ação da empresa latino-americana (Tabela A2). Este resultado é um sinal que, de fato, esta disponibilidade de ativos tangíveis para uso como garantia pode estar sendo um fator que favorece a utilização de dívida e um desestímulo adicional para a emissão de ações.

Sobre o endividamento, importante fonte de financiamento que tende a ser priorizada em relação à emissão de ações de acordo com a Teoria Peckingorder, alguns modelos específicos foram estimados por mínimos quadrados ordinários, tendo-se o endividamento como variável dependente. A estimação destes modelos confirmou o forte efeito positivo da tangibilidade de ativos sobre o endividamento da empresa latino-americana (Tabela A3). Destaque-se também o efeito negativo da rentabilidade sobre o endividamento indicando a preferência de empresas mais rentáveis em não recorrer ao endividamento e utilizarem fluxo de caixa para financiar-se.

A relevância das oportunidades de crescimento para a necessidade de financiamento da empresa motivou a avaliação de possível mudança de comportamento de grandes acionistas frente a distintos cenários de oportunidades de investimento vividos pela empresa. Variações do modelo da equação (1) foram estimados separadamente para sub amostras de empresas visando avaliar esta possível mudança de comportamento de grandes acionistas. Esta argumentação advinda do contexto de agência sugere a utilização de dívida como instrumento de monitoração da direção da empresa uma vez que fluxo de caixa comprometido com pagamento de dívida minimiza a possibilidade 
Tabela A1

Estimação de modelos da emissão de ação na América Latina considerando endividamento

\begin{tabular}{|c|c|c|c|c|c|c|}
\hline variável & (i) & (ii) & (iii) & (iv) & (v) & (vi) \\
\hline ACMAJOR & $\begin{array}{c}-0,2183^{* * *} * \\
(0,074)\end{array}$ & & & & & \\
\hline CPROP1 & & $\begin{array}{c}-0,4784 * * * \\
(0,143)\end{array}$ & & & & \\
\hline CPROP2 & & & $\begin{array}{c}-0,8456^{* * *} \\
(0,148)\end{array}$ & & & \\
\hline CPROP3 & & & & $\begin{array}{c}-1,0817 * * * \\
(0,158)\end{array}$ & & \\
\hline CPROP4 & & & & & $\begin{array}{c}-1,1956^{* * *} \\
(0,168)\end{array}$ & \\
\hline CPROP5 & & & & & & $\begin{array}{c}-1,2688 * * * \\
(0,174)\end{array}$ \\
\hline ROA & $\begin{array}{c}-2,7306^{* * * *} \\
(0,385)\end{array}$ & $\begin{array}{c}-2,7085^{* * * *} \\
(0,386)\end{array}$ & $\begin{array}{c}-2,6652^{* * * *} \\
(0,387)\end{array}$ & $\begin{array}{c}-2,6769^{* * *} \\
(0,391)\end{array}$ & $\begin{array}{c}-2,6863^{* * *} \\
(0,390)\end{array}$ & $\begin{array}{c}-2,6876^{* * * *} \\
(0,390)\end{array}$ \\
\hline TAM & $\begin{array}{l}0,2221^{* * * *} \\
(0,026)\end{array}$ & $\begin{array}{l}0,2161 * * * \\
(0,026)\end{array}$ & $\begin{array}{l}0,2124 * * * \\
(0,026)\end{array}$ & $\begin{array}{l}0,2077 \text { **** } \\
(0,026)\end{array}$ & $\begin{array}{l}0,2034 * * * \\
(0,026)\end{array}$ & $\begin{array}{l}0,2007 * * * \\
(0,026)\end{array}$ \\
\hline OPCRESC & $\begin{array}{l}0,4004 * * * \\
(0,048)\end{array}$ & $\begin{array}{l}0,3961 * * * \\
(0,048)\end{array}$ & $\begin{array}{l}0,3832 * * * \\
(0,048)\end{array}$ & $\begin{array}{l}0,3802^{* * * *} \\
(0,048)\end{array}$ & $\begin{array}{l}0,3814 * * * \\
(0,048)\end{array}$ & $\begin{array}{l}0,3796^{* * * *} \\
(0,048)\end{array}$ \\
\hline ENDIV & $\begin{array}{r}-0,2679 \\
(0,298)\end{array}$ & $\begin{array}{r}-0,2483 \\
(0,296)\end{array}$ & $\begin{array}{r}-0,2497 \\
(0,296)\end{array}$ & $\begin{array}{r}-0,2476 \\
(0,297)\end{array}$ & $\begin{array}{r}-0,2445 \\
(0,297)\end{array}$ & $\begin{array}{r}-0,2459 \\
(0,297)\end{array}$ \\
\hline n. obs. & $\begin{array}{r}4866 \\
0084\end{array}$ & $\begin{array}{r}4866 \\
0084\end{array}$ & $\begin{array}{r}4866 \\
0088\end{array}$ & $\begin{array}{r}4866 \\
0090\end{array}$ & $\begin{array}{r}4866 \\
0.091\end{array}$ & $\begin{array}{r}4866 \\
0092\end{array}$ \\
\hline $\begin{array}{l}\text { pseudo R2 } \\
\text { Wald chi2 }\end{array}$ & $\begin{array}{r}0,084 \\
362,65\end{array}$ & $\begin{array}{r}0,084 \\
363,75\end{array}$ & $\begin{array}{r}0,088 \\
383,92\end{array}$ & $\begin{array}{r}0,090 \\
396,81\end{array}$ & $\begin{array}{r}0,091 \\
400,74\end{array}$ & 402,41 \\
\hline p-value & 0,000 & 0,000 & 0,000 & 0,000 & 0,000 & 0,000 \\
\hline
\end{tabular}

Notas: A variável dependente é a emissão de ação (EMI_AÇĀ). Variáveis independentes: acionista majoritário (ACMAJOR); concentração de propriedade nas mãos do principal acionista (CPROP1); concentração de propriedade nas mãos dos dois principais acionistas (CPROP2); concentração de propriedade nas mãos dos três principais acionistas (CPROP3); concentração de propriedade nas mãos dos quatro principais acionistas (CPROP4); concentração de propriedade nas mãos dos cinco principais acionistas (CPROP5); rentabilidade (ROA); tamanho (TAM); oportunidades de crescimento (OPCRESC); endividamento (ENDIV). Foram estimados modelos logit. Coeficientes estimados e desvios padrões robustos à heteroscedasticidade (entre parênteses) referentes à estimação do modelo da equação (1). Modelos incluem dummies de país, setor e ano. ***,** e * denotam significância estatística dos coeficientes em $1 \%, 5 \%$ e $10 \%$, respectivamente. 


\section{Tabela A2}

\section{Estimação de modelos da emissão de ação na América Latina considerando tangibilidade dos ativos}

\begin{tabular}{|c|c|c|c|c|c|c|}
\hline variável & (i) & (ii) & (iii) & (iv) & (v) & (vi) \\
\hline ACMAJOR & $\begin{array}{c}-0,2678 * * * \\
(0,068)\end{array}$ & & & & & \\
\hline CPROP1 & & $\begin{array}{c}-0,5008^{* * * *} \\
(0,131)\end{array}$ & & & & \\
\hline CPROP2 & & & $\begin{array}{c}-0,8872 * * * \\
(0,138)\end{array}$ & & & \\
\hline CPROP3 & & & & $\begin{array}{c}-1,0881 * * * \\
(0,148)\end{array}$ & & \\
\hline CPROP4 & & & & & $\begin{array}{c}-1,1917 * * * \\
(0,157)\end{array}$ & \\
\hline CPROP5 & & & & & & $\begin{array}{c}-1,2467 * * * \\
(0,164)\end{array}$ \\
\hline $\mathrm{ROA}$ & $\begin{array}{c}-1,8241 \text { *** } \\
(0,337)\end{array}$ & $\begin{array}{c}-1,8112^{* * * *} \\
(0,338)\end{array}$ & $\begin{array}{c}-1,7830^{* * * *} \\
(0,337)\end{array}$ & $\begin{array}{c}-1,7964 * * * \\
(0,338)\end{array}$ & $\begin{array}{c}-1,8034 * * * \\
(0,339)\end{array}$ & $\begin{array}{c}-1,8080 * * * \\
(0,339)\end{array}$ \\
\hline TAM & $\begin{array}{l}0,2289 * * * \\
(0,024)\end{array}$ & $\begin{array}{l}0,2226 * * * \\
(0,024)\end{array}$ & $\begin{array}{l}0,2169 * * * \\
(0,024)\end{array}$ & $\begin{array}{l}0,2121 * * * \\
(0,024)\end{array}$ & $\begin{array}{l}0,2082 * * * \\
(0,024)\end{array}$ & $\begin{array}{l}0,2061 * * * \\
(0,024)\end{array}$ \\
\hline OPCRESC & $\begin{array}{l}0,3182 \text { *** } \\
(0,042)\end{array}$ & $\begin{array}{l}0,3148 * * * \\
(0,042)\end{array}$ & $\begin{array}{l}0,3013 * * * \\
(0,042)\end{array}$ & $\begin{array}{l}0,2975 * * * \\
(0,042)\end{array}$ & $\begin{array}{l}0,2973 \text { *** } \\
(0,042)\end{array}$ & $\begin{array}{l}0,2960 * * * \\
(0,042)\end{array}$ \\
\hline TANG & $\begin{array}{c}-0,8009 * * * \\
(0,156)\end{array}$ & $\begin{array}{c}-0,7907 * * * \\
(0,156)\end{array}$ & $\begin{array}{c}-0,7544 * * * \\
(0,157)\end{array}$ & $\begin{array}{c}-0,7436 * * * \\
(0,157)\end{array}$ & $\begin{array}{c}-0,7452^{* * * *} \\
(0,157)\end{array}$ & $\begin{array}{c}-0,7455^{* * * *} \\
(0,157)\end{array}$ \\
\hline n. obs. & 5620 & 5620 & 5620 & 5620 & 5620 & 5620 \\
\hline pseudo R2 & 0,095 & 0,095 & 0,099 & 0,101 & 0,102 & 0,102 \\
\hline Wald chi2 & 492,18 & 490,56 & 512,61 & 521,39 & 523,63 & 523,68 \\
\hline p-value & 0,000 & 0,000 & 0,000 & 0,000 & 0,000 & 0,000 \\
\hline
\end{tabular}

Notas: A variável dependente é o endividamento (ENDIV). Variáveis independentes: acionista majoritário (ACMAJOR); concentração de propriedade nas mãos do principal acionista (CPROP1); concentração de propriedade nas mãos dos dois principais acionistas (CPROP2); concentração de propriedade nas mãos dos três principais acionistas (CPROP3); concentração de propriedade nas mãos dos quatro principais acionistas (CPROP4); concentração de propriedade nas mãos dos cinco principais acionistas (CPROP5); rentabilidade (ROA); tamanho (TAM); oportunidades de crescimento (OPCRESC); emissão de ação (EMI_AÇÃO); tangibilidade (TANG). Foram estimados modelos pelo método dos mínimos quadrados ordinários. Coeficientes estimados e desvios padrões robustos à heteroscedasticidade (entre parênteses) referentes à estimação do modelo da equação (1). Modelos incluem dummies de país, setor e ano. ***, ** e * denotam significância estatística dos coeficientes em 1\%, 5\% e 10\%, respectivamente. 


\section{Tabela A3}

\section{Estimação de modelos de endividamento na América Latina}

\begin{tabular}{|c|c|c|c|c|c|c|}
\hline variável & (i) & (ii) & (iii) & (iv) & (v) & (vi) \\
\hline ACMAJOR & $\begin{array}{r}-0,0028 \\
(0,003)\end{array}$ & & & & & \\
\hline CPROP1 & & $\begin{array}{r}-0,0062 \\
(0,007)\end{array}$ & & & & \\
\hline CPROP2 & & & $\begin{array}{r}-0,0094 \\
(0,007)\end{array}$ & & & \\
\hline CPROP3 & & & & $\begin{array}{r}-0,0081 \\
(0,008)\end{array}$ & & \\
\hline CPROP4 & & & & & $\begin{array}{r}-0,0069 \\
(0,008)\end{array}$ & \\
\hline CPROP5 & & & & & & $\begin{array}{r}-0,0071 \\
(0,009)\end{array}$ \\
\hline ROA & $\begin{array}{c}-0,1207 * * * \\
(0,017)\end{array}$ & $\begin{array}{c}-0,1205 * * * \\
(0,017)\end{array}$ & $\begin{array}{c}-0,1202 * * * \\
(0,017)\end{array}$ & $\begin{array}{c}-0,1205^{* * *} \\
(0,017)\end{array}$ & $\begin{array}{c}-0,1207 * * * \\
(0,017)\end{array}$ & $\begin{array}{c}-0,1207 * * * \\
(0,017)\end{array}$ \\
\hline TAM & $\begin{array}{l}0,0145^{* * * *} \\
(0,001)\end{array}$ & $\begin{array}{l}0,0145 * * * \\
(0,001)\end{array}$ & $\begin{array}{l}0,0144 * * * \\
(0,001)\end{array}$ & $\begin{array}{l}0,0144 * * * \\
(0,001)\end{array}$ & $\begin{array}{l}0,0144 * * * \\
(0,001)\end{array}$ & $\begin{array}{l}0,0144 * * * \\
(0,001)\end{array}$ \\
\hline OPCRESC & $\begin{array}{l}0,0072 * * * \\
(0,002)\end{array}$ & $\begin{array}{l}0,0072 * * * \\
(0,002)\end{array}$ & $\begin{array}{l}0,0071 * * * \\
(0,002)\end{array}$ & $\begin{array}{l}0,0071 * * * \\
(0,002)\end{array}$ & $\begin{array}{l}0,0072 * * * \\
(0,002)\end{array}$ & $\begin{array}{l}0,0072 \text { *** } \\
(0,002)\end{array}$ \\
\hline EMI_AÇÃO & $\begin{array}{l}0,0003 \\
(0,004)\end{array}$ & $\begin{array}{l}0,0002 \\
(0,004)\end{array}$ & $\begin{array}{l}0,0000 \\
(0,004)\end{array}$ & $\begin{array}{r}0,0000 \\
(0,004)\end{array}$ & $\begin{array}{r}0,0001 \\
(0,004)\end{array}$ & $\begin{array}{l}0,0001 \\
(0,004)\end{array}$ \\
\hline TANG & $\begin{array}{l}0,0956 * * * \\
(0,008)\end{array}$ & $\begin{array}{l}0,0957 * * * \\
(0,008)\end{array}$ & $\begin{array}{l}0,0959 * * * \\
(0,008)\end{array}$ & $\begin{array}{l}0,0957 * * * \\
(0,008)\end{array}$ & $\begin{array}{l}0,0956 * * * \\
(0,008)\end{array}$ & $\begin{array}{l}0,0956^{* * * *} \\
(0,008)\end{array}$ \\
\hline n. obs. & 4859 & 4859 & 4859 & 4859 & 4859 & 4859 \\
\hline pseudo R2 & 0,142 & 0,142 & 0,142 & 0,142 & 0,142 & 0,142 \\
\hline Wald chi 2 & 22,03 & 21,98 & 21,96 & 21,94 & 21,93 & 21,93 \\
\hline p-value & 0,000 & 0,000 & 0,000 & 0,000 & 0,000 & 0,000 \\
\hline
\end{tabular}

Notas: A variável dependente é o endividamento (ENDIV). Variáveis independentes: acionista majoritário (ACMAJOR); concentração de propriedade nas mãos do principal acionista (CPROP1); concentração de propriedade nas mãos dos dois principais acionistas (CPROP2); concentração de propriedade nas mãos dos três principais acionistas (CPROP3); concentração de propriedade nas mãos dos quatro principais acionistas (CPROP4); concentração de propriedade nas mãos dos cinco principais acionistas (CPROP5); rentabilidade (ROA); tamanho (TAM); oportunidades de crescimento (OPCRESC); emissão de ação (EMI_AÇÃO); tangibilidade (TANG). Foram estimados modelos pelo método dos mínimos quadrados ordinários. Coeficientes estimados e desvios padrões robustos à heteroscedasticidade (entre parênteses) referentes à estimação do modelo da equação (1). Modelos incluem dummies de país, setor e ano. ***, ** e* denotam significância estatística dos coeficientes em $1 \%, 5 \%$ e $10 \%$, respectivamente. 
de problemas de fluxo de caixa livre (Jensen; 1986; López-Iturriaga and Crisóstomo; 2010). Espera-se que em empresas com mais oportunidades de crescimento grandes acionistas poderiam ser mais propensos a aceitar emissão de ação visando aproveitar todas as oportunidades de investimento disponíveis. Por outro lado, em empresas que dispõem de menos oportunidades de crescimento, grandes acionistas seriam ainda mais resistentes a emitir ação, aproveitando o uso da dívida como instrumento de monitoração executiva para restringir o fluxo de caixa livre. Os resultados para ambos os grupos de empresas, com mais oportunidades de crescimento (Tabela A4) e com menos oportunidades de crescimento (Tabela A5), são qualitativamente os mesmos, ratificando a grande dificuldade de emissão de ação no mercado latinoamericano decorrente da alta concentração de propriedade, seja pelo receio de perda de controle, ou ainda pela proposta de agência de uso da dívida como instrumento adicional de monitoração executiva.

A mais baixa rentabilidade também poderia ser um fator que favorecesse a emissão de ação, considerando que a empresa disporia de menos fluxo de caixa para honrar compromisso de dívida como também para financiar-se com recursos próprios oriundos do lucro retido para investimento. No entanto, como se pode observar nas Tabelas A6 e A7, os resultados são qualitativamente os mesmos no sentido de indicar o efeito negativo da alta concentração de propriedade sobre a probabilidade da empresa em decidir pela emissão de ações. Esta resistência é similar para empresas com mais alta (Tabela A6) ou mais baixa rentabilidade (Tabela A7). Desta forma, não há indício de mudança de comportamento de grandes acionistas com relação à emissão de ações em função do quadro de rentabilidade da empresa. 
Tabela A4

Estimação de modelos de emissão de ação para empresas com mais oportunidades de crescimento na América Latina

\begin{tabular}{|c|c|c|c|c|c|c|}
\hline variável & (i) & (ii) & (iii) & (iv) & (v) & (vi) \\
\hline ACMAJOR & $\begin{array}{c}-0,2028 * * \\
(0,100)\end{array}$ & & & & & \\
\hline CPROP1 & & $\begin{array}{c}-0,6444 * * * \\
(0,193)\end{array}$ & & & & \\
\hline CPROP2 & & & $\begin{array}{c}-0,9583^{* * * *} \\
(0,200)\end{array}$ & & & \\
\hline CPROP3 & & & & $\begin{array}{c}-1,2137 * * * \\
(0,214)\end{array}$ & & \\
\hline CPROP4 & & & & & $\begin{array}{c}-1,3279 * * * \\
(0,226)\end{array}$ & \\
\hline CPROP5 & & & & & & $\begin{array}{c}-1,3792 * * * \\
(0,233)\end{array}$ \\
\hline ROA & $\begin{array}{c}-3,0305 * * * \\
(0,555)\end{array}$ & $\begin{array}{c}-3,0234 * * * \\
(0,558)\end{array}$ & $\begin{array}{c}-3,0228 * * * \\
(0,559)\end{array}$ & $\begin{array}{l}-3,037 * * * \\
(0,561)\end{array}$ & $\begin{array}{c}-3,0323 * * * \\
(0,561)\end{array}$ & $\begin{array}{c}-3,0221 \text { *** } \\
(0,561)\end{array}$ \\
\hline TAM & $\begin{array}{l}0,1964 * * * \\
(0,036)\end{array}$ & $\begin{array}{l}0,1904 * * * \\
(0,036)\end{array}$ & $\begin{array}{l}0,1918 * * * \\
(0,036)\end{array}$ & $\begin{array}{l}0,1883^{* * * *} \\
(0,036)\end{array}$ & $\begin{array}{l}0,1837 * * * \\
(0,036)\end{array}$ & $\begin{array}{l}0,1803 \text { *** } \\
(0,036)\end{array}$ \\
\hline OPCRESC & $\begin{array}{l}0,2880^{* * * *} \\
(0,056)\end{array}$ & $\begin{array}{l}0,2762 * * * \\
(0,056)\end{array}$ & $\begin{array}{l}0,2694 * * * \\
(0,056)\end{array}$ & $\begin{array}{l}0,2659 * * * \\
(0,056)\end{array}$ & $\begin{array}{l}0,2676 * * * \\
(0,056)\end{array}$ & $\begin{array}{l}0,2661 * * * \\
(0,056)\end{array}$ \\
\hline ENDIV & $\begin{array}{r}-0,4731 \\
(0,392)\end{array}$ & $\begin{array}{r}-0,4615 \\
(0,391)\end{array}$ & $\begin{array}{r}-0,4791 \\
(0,392)\end{array}$ & $\begin{array}{r}-0,4837 \\
(0,393)\end{array}$ & $\begin{array}{r}-0,4735 \\
(0,393)\end{array}$ & $\begin{array}{r}-0,4642 \\
(0,393)\end{array}$ \\
\hline TANG & $\begin{array}{c}-1,1727 * * * \\
(0,247)\end{array}$ & $\begin{array}{c}-1,1494 * * * \\
(0,246)\end{array}$ & $\begin{array}{c}-1,1152 * * * \\
(0,246)\end{array}$ & $\begin{array}{c}-1,1032^{* * * *} \\
(0,246)\end{array}$ & $\begin{array}{c}-1,1075 * * * \\
(0,246)\end{array}$ & $\begin{array}{c}-1,1082 * * * \\
(0,246)\end{array}$ \\
\hline n. obs. & 2487 & 2487 & 2487 & 2487 & 2487 & 2487 \\
\hline pseudo R2 & 0,118 & 0,121 & 0,125 & 0,127 & 0,128 & 0,128 \\
\hline Wald chi2 & 270,77 & 278,13 & 289,19 & 296,69 & 298,39 & 298,89 \\
\hline p-value & 0,000 & 0,000 & 0,000 & 0,000 & 0,000 & 0,000 \\
\hline
\end{tabular}

Notas: A variável dependente é a emissão de ação (EMI_AÇÃO). Variáveis independentes: acionista majoritário (ACMAJOR); concentração de propriedade nas mãos do principal acionista (CPROP1); concentração de propriedade nas mãos dos dois principais acionistas (CPROP2); concentração de propriedade nas mãos dos três principais acionistas (CPROP3); concentração de propriedade nas mãos dos quatro principais acionistas (CPROP4); concentração de propriedade nas mãos dos cinco principais acionistas (CPROP5); rentabilidade (ROA); tamanho (TAM); oportunidades de crescimento (OPCRESC); endividamento (ENDIV); tangibilidade (TANG). Foram estimados modelos logit. Coeficientes estimados e desvios padrões robustos à heteroscedasticidade (entre parênteses) referentes à estimação do modelo da equação (1). Modelos incluem dummies de país, setor e ano. ***, ** e * denotam significância estatística dos coeficientes em $1 \%, 5 \%$ e $10 \%$, respectivamente. 
Tabela A5

Estimação de modelos de emissão de ação para empresas com menos oportunidades de crescimento na América Latina

\begin{tabular}{|c|c|c|c|c|c|c|}
\hline variável & (i) & (ii) & (iii) & (iv) & (v) & (vi) \\
\hline ACMAJOR & $\begin{array}{r}-0,0813 \\
(0,120)\end{array}$ & & & & & \\
\hline CPROP1 & & $\begin{array}{r}0,0336 \\
(0,228)\end{array}$ & & & & \\
\hline CPROP2 & & & $\begin{array}{c}-0,4194 * \\
(0,245)\end{array}$ & & & \\
\hline CPROP3 & & & & $\begin{array}{c}-0,6480 * * \\
(0,266)\end{array}$ & & \\
\hline CPROP4 & & & & & $\begin{array}{c}-0,7452 * * * \\
(0,286)\end{array}$ & \\
\hline CPROP5 & & & & & & $\begin{array}{c}-0,8239 * * * \\
(0,301)\end{array}$ \\
\hline ROA & $\begin{array}{c}-1,9972 * * * \\
(0,604)\end{array}$ & $\begin{array}{c}-2,0310 * * * \\
(0,605)\end{array}$ & $\begin{array}{c}-1,9235 * * * \\
(0,606)\end{array}$ & $\begin{array}{c}-1,9084 * * * \\
(0,608)\end{array}$ & $\begin{array}{c}-1,9144 * * * \\
(0,610)\end{array}$ & $\begin{array}{c}-1,9179 * * * * \\
(0,610)\end{array}$ \\
\hline TAM & $\begin{array}{l}0,2481 \text { *** } \\
(0,042)\end{array}$ & $\begin{array}{l}0,2496 * * * \\
(0,042)\end{array}$ & $\begin{array}{l}0,2399 * * * \\
(0,042)\end{array}$ & $\begin{array}{l}0,2332 * * * \\
(0,042)\end{array}$ & $\begin{array}{l}0,2296 * * * \\
(0,043)\end{array}$ & $\begin{array}{l}0,2275^{* * * *} \\
(0,043)\end{array}$ \\
\hline OPCRESC & $\begin{array}{l}1,3066^{* * * *} \\
(0,334)\end{array}$ & $\begin{array}{l}1,2961 * * * \\
(0,334)\end{array}$ & $\begin{array}{l}1,3039 * * * \\
(0,335)\end{array}$ & $\begin{array}{l}1,3025 * * * \\
(0,335)\end{array}$ & $\begin{array}{l}1,3003 \text { *** } \\
(0,336)\end{array}$ & $\begin{array}{l}1,3008 * * * \\
(0,337)\end{array}$ \\
\hline ENDIV & $\begin{array}{r}0,2242 \\
(0,516)\end{array}$ & $\begin{array}{r}0,2372 \\
(0,515)\end{array}$ & $\begin{array}{r}0,2126 \\
(0,515)\end{array}$ & $\begin{array}{l}0,2079 \\
(0,515)\end{array}$ & $\begin{array}{l}0,2109 \\
(0,515)\end{array}$ & $\begin{array}{r}0,2051 \\
(0,515)\end{array}$ \\
\hline TANG & $\begin{array}{c}-0,7959 * * * \\
(0,257)\end{array}$ & $\begin{array}{c}-0,8032 * * * \\
(0,257)\end{array}$ & $\begin{array}{c}-0,7682^{* * * *} \\
(0,258)\end{array}$ & $\begin{array}{c}-0,7534 * * * \\
(0,259)\end{array}$ & $\begin{array}{c}-0,7520 * * * \\
(0,259)\end{array}$ & $\begin{array}{c}-0,7506^{* * * *} \\
(0,259)\end{array}$ \\
\hline n. obs. & 2372 & 2372 & 2372 & 2372 & 2372 & 2372 \\
\hline pseudo R2 & 0,097 & 0,097 & 0,098 & 0,099 & 0,100 & 0,100 \\
\hline Wald chi2 & 212,56 & 210,73 & 216,33 & 219,17 & 219,92 & 220,51 \\
\hline p-value & 0,000 & 0,000 & 0,000 & 0,000 & 0,000 & 0,000 \\
\hline
\end{tabular}

Notas: A variável dependente é a emissão de ação (EMI_AÇÃO). Variáveis independentes: acionista majoritário (ACMAJOR); concentração de propriedade nas mãos do principal acionista (CPROP1); concentração de propriedade nas mãos dos dois principais acionistas (CPROP2); concentração de propriedade nas mãos dos três principais acionistas (CPROP3); concentração de propriedade nas mãos dos quatro principais acionistas (CPROP4); concentração de propriedade nas mãos dos cinco principais acionistas (CPROP5); rentabilidade (ROA); tamanho (TAM); oportunidades de crescimento (OPCRESC); endividamento (ENDIV); tangibilidade (TANG). Foram estimados modelos logit. Coeficientes estimados e desvios padrões robustos à heteroscedasticidade (entre parênteses) referentes à estimação do modelo da equação (1). Modelos incluem dummies de país, setor e ano. ***, ** e * denotam significância estatística dos coeficientes em $1 \%, 5 \%$ e $10 \%$, respectivamente. 
Tabela A6

Estimação de modelos de emissão de ação para empresas com mais rentabilidade na América Latina

\begin{tabular}{|c|c|c|c|c|c|c|}
\hline variável & (i) & (ii) & (iii) & (iv) & (v) & (vi) \\
\hline ACMAJOR & $\begin{array}{r}-0,0743 \\
(0,106)\end{array}$ & & & & & \\
\hline CPROP1 & & $\begin{array}{r}-0,2522 \\
(0,202)\end{array}$ & & & & \\
\hline CPROP2 & & & $\begin{array}{c}-0,7220^{* * * *} \\
(0,209)\end{array}$ & & & \\
\hline CPROP3 & & & & $\begin{array}{c}-1,1074 * * * \\
(0,227)\end{array}$ & & \\
\hline CPROP4 & & & & & $\begin{array}{c}-1,3193 * * * \\
(0,242)\end{array}$ & \\
\hline CPROP5 & & & & & & $\begin{array}{c}-1,4381 * * * \\
(0,254)\end{array}$ \\
\hline ROA & $\begin{array}{l}0,1458 * * * \\
(0,030)\end{array}$ & $\begin{array}{l}0,1445^{* * *} \\
(0,036)\end{array}$ & $\begin{array}{l}0,1460 * * * \\
(0,036)\end{array}$ & $\begin{array}{l}0,1440 * * * \\
(0,036)\end{array}$ & $\begin{array}{l}0,1396 * * * \\
(0,036)\end{array}$ & $\begin{array}{l}0,1365^{\text {**** }} \\
(0,036)\end{array}$ \\
\hline TAM & $\begin{array}{l}0,3026^{* * * *} \\
(0,056)\end{array}$ & $\begin{array}{l}0,2981 * * * \\
(0,056)\end{array}$ & $\begin{array}{l}0,2777 * * * \\
(0,056)\end{array}$ & $\begin{array}{l}0,2661 * * * \\
(0,056)\end{array}$ & $\begin{array}{l}0,2640 * * * \\
(0,056)\end{array}$ & $\begin{array}{l}0,2609 * * * \\
(0,056)\end{array}$ \\
\hline OPCRESC & $\begin{array}{r}0,4204 \\
(0,456)\end{array}$ & $\begin{array}{l}0,4151 \\
(0,455)\end{array}$ & $\begin{array}{r}0,3565 \\
(0,456)\end{array}$ & $\begin{array}{r}0,3409 \\
(0,457)\end{array}$ & $\begin{array}{l}0,3423 \\
(0,457)\end{array}$ & $\begin{array}{l}0,3481 \\
(0,457)\end{array}$ \\
\hline ENDIV & $\begin{array}{c}-1,1118 * * * \\
(0,258)\end{array}$ & $\begin{array}{c}-1,1045^{* * *} \\
(0,258)\end{array}$ & $\begin{array}{c}-1,0615^{* * * *} \\
(0,258)\end{array}$ & $\begin{array}{c}-1,0490 * * * \\
(0,258)\end{array}$ & $\begin{array}{c}-1,0485^{* * * *} \\
(0,258)\end{array}$ & $\begin{array}{c}-1,0491 * * * \\
(0,259)\end{array}$ \\
\hline n. obs. & 2502 & 2502 & 2502 & 2502 & 2502 & 2502 \\
\hline pseudo R2 & 0,090 & 0,090 & 0,094 & 0,098 & 0,100 & 0,101 \\
\hline Wald chi2 & 215,05 & 216,03 & 226,97 & 238,27 & 242,91 & 243,70 \\
\hline p-value & 0,000 & 0,000 & 0,000 & 0,000 & 0,000 & 0,000 \\
\hline
\end{tabular}

Notas: A variável dependente é a emissão de ação (EMI_AÇAO). Variáveis independentes: acionista majoritário (ACMAJOR); concentração de propriedade nas mãos do principal acionista (CPROP1); concentração de propriedade nas mãos dos dois principais acionistas (CPROP2); concentração de propriedade nas mãos dos três principais acionistas (CPROP3); concentração de propriedade nas mãos dos quatro principais acionistas (CPROP4); concentração de propriedade nas mãos dos cinco principais acionistas (CPROP5); tamanho (TAM); oportunidades de crescimento (OPCRESC); endividamento (ENDIV); tangibilidade (TANG). Foram estimados modelos logit. Coeficientes estimados e desvios padrões robustos à heteroscedasticidade (entre parênteses) referentes à estimação do modelo da equação (1). Modelos incluem dummies de país, setor e ano. ***,** e* denotam significância estatística dos coeficientes em $1 \%, 5 \%$ e $10 \%$, respectivamente. 
Tabela A7

Estimação de modelos de emissão de ação para empresas com menos rentabilidade na América Latina

\begin{tabular}{|c|c|c|c|c|c|c|}
\hline variável & (i) & (ii) & (iii) & (iv) & (v) & (vi) \\
\hline ACMAJOR & $\begin{array}{c}-0,3120^{* * * *} \\
(0,108)\end{array}$ & & & & & \\
\hline CPROP1 & & $\begin{array}{c}-0,5915^{* * *} * \\
(0,209)\end{array}$ & & & & \\
\hline CPROP2 & & & $\begin{array}{c}-0,8718^{* * * *} \\
(0,219)\end{array}$ & & & \\
\hline CPROP3 & & & & $\begin{array}{c}-0,9761^{* * * *} \\
(0,231)\end{array}$ & & \\
\hline CPROP4 & & & & & $\begin{array}{c}-1,0071^{* * *} * \\
(0,243)\end{array}$ & \\
\hline CPROP5 & & & & & & $\begin{array}{c}-1,0439^{* * * *} \\
(0,251)\end{array}$ \\
\hline ROA & $\begin{array}{l}0,2064 \text { *** } \\
(0,037)\end{array}$ & $\begin{array}{l}0,1989^{* * *} \\
(0,037)\end{array}$ & $\begin{array}{l}0,1927 * * * \\
(0,037)\end{array}$ & $\begin{array}{l}0,1888^{* * * *} \\
(0,037)\end{array}$ & $\begin{array}{l}0,1869^{* * * *} \\
(0,037)\end{array}$ & $\begin{array}{l}0,1859 \text { *** } \\
(0,037)\end{array}$ \\
\hline TAM & $\begin{array}{l}0,4678 * * * \\
(0,087)\end{array}$ & $\begin{array}{l}0,4630 * * * \\
(0,088)\end{array}$ & $\begin{array}{l}0,4596^{* * * *} \\
(0,088)\end{array}$ & $\begin{array}{l}0,4578 * * * \\
(0,088)\end{array}$ & $\begin{array}{l}0,4569^{* * *} \\
(0,088)\end{array}$ & $\begin{array}{l}0,4556^{* * * *} \\
(0,088)\end{array}$ \\
\hline OPCRESC & $\begin{array}{r}-0,0349 \\
(0,394)\end{array}$ & $\begin{array}{r}-0,0044 \\
(0,392)\end{array}$ & $\begin{array}{r}0,0116 \\
(0,393)\end{array}$ & $\begin{array}{l}0,0100 \\
(0,393)\end{array}$ & $\begin{array}{l}0,0114 \\
(0,393)\end{array}$ & $\begin{array}{r}0,0028 \\
(0,393)\end{array}$ \\
\hline ENDIV & $\begin{array}{c}-0,7600^{* * * *} \\
(0,237)\end{array}$ & $\begin{array}{c}-0,7214 * * * \\
(0,238)\end{array}$ & $\begin{array}{c}-0,6952^{* * * *} \\
(0,238)\end{array}$ & $\begin{array}{l}-0,6849^{* * *} \\
(0,238)\end{array}$ & $\begin{array}{c}-0,6919^{* * *} \\
(0,238)\end{array}$ & $\begin{array}{c}-0,6926 \text { *** } \\
(0,238)\end{array}$ \\
\hline $\begin{array}{l}\text { n. obs. } \\
\text { pseudo R2 } \\
\text { Wald chi2 } \\
\text { p-value }\end{array}$ & $\begin{array}{r}2387 \\
0,085 \\
191,59 \\
0,000\end{array}$ & $\begin{array}{r}2374 \\
0,090 \\
200,19 \\
0,000\end{array}$ & $\begin{array}{r}2374 \\
0,092 \\
204,95 \\
0,000\end{array}$ & $\begin{array}{r}2374 \\
0,093 \\
206,86 \\
0,000\end{array}$ & $\begin{array}{r}2374 \\
0,093 \\
206,81 \\
0,000\end{array}$ & $\begin{array}{r}2374 \\
0,093 \\
206,69 \\
0,000\end{array}$ \\
\hline \multicolumn{7}{|c|}{$\begin{array}{l}\text { Notas: A variável dependente é a emissão de ação (EMI_AÇAO). Variáveis independentes: acionista } \\
\text { majoritário (ACMAJOR); concentração de propriedade nas mãos do principal acionista (CPROP1); } \\
\text { concentração de propriedade nas mãos dos dois principais acionistas (CPROP2); concentração de pro- } \\
\text { priedade nas mãos dos três principais acionistas (CPROP3); concentração de propriedade nas mãos dos } \\
\text { quatro principais acionistas (CPROP4); concentração de propriedade nas mãos dos cinco principais } \\
\text { acionistas (CPROP5); tamanho (TAM); oportunidades de crescimento (OPCRESC); endividamento } \\
\text { (ENDIV); tangibilidade (TANG). Foram estimados modelos logit. Coeficientes estimados e desvios } \\
\text { padrões robustos à heteroscedasticidade (entre parênteses) referentes à estimação do modelo da equa- } \\
\text { ção (1). Modelos incluem dummies de país, setor e ano. } * * * \text {, ** e } * \text { denotam significância estatística } \\
\text { dos coeficientes em } 1 \%, 5 \% \text { e } 10 \% \text {, respectivamente. }\end{array}$} \\
\hline
\end{tabular}

